OPEN ACCESS

Edited by:

Fernando Guimaraes,

University of Queensland, Australia

Reviewed by:

Katharine Goodall,

Monash University, Australia

Alyce Mayfosh,

La Trobe University, Australia

${ }^{*}$ Correspondence:

Alicja J. Copik

alicja.copik@ucf.edu

Specialty section: This article was submitted to

Cancer Immunity and Immunotherapy,

a section of the journal

Frontiers in Immunology

Received: 11 March 2021

Accepted: 09 April 2021

Published: 28 April 2021

Citation:

Shaver KA, Croom-Perez TJ and Copik AJ (2021) Natural Killer Cells:

The Linchpin for Successful Cancer Immunotherapy.

Front. Immunol. 12:679117. doi: 10.3389/fimmu.2021.679117

\section{Natural Killer Cells: The Linchpin for Successful Cancer Immunotherapy}

\author{
Kari A. Shaver ${ }^{1}$, Tayler J. Croom-Perez ${ }^{2}$ and Alicja J. Copik ${ }^{2 *}$ \\ ${ }^{1}$ College of Medicine, University of Central Florida, Orlando, FL, United States, ${ }^{2}$ Burnett School of Biomedical Science, \\ College of Medicine, University of Central Florida, Orlando, FL, United States
}

Cancer immunotherapy is a highly successful and rapidly evolving treatment modality that works by augmenting the body's own immune system. While various immune stimulation strategies such as PD-1/PD-L1 or CTLA-4 checkpoint blockade result in robust responses, even in patients with advanced cancers, the overall response rate is low. While immune checkpoint inhibitors are known to enhance cytotoxic T cells' antitumor response, current evidence suggests that immune responses independent of cytotoxic $T$ cells, such as Natural Killer (NK) cells, play crucial role in the efficacy of immunotherapeutic interventions. NK cells hold a distinct role in potentiating the innate immune response and activating the adaptive immune system. This review highlights the importance of the early actions of the NK cell response and the pivotal role NK cells hold in priming the immune system and setting the stage for successful response to cancer immunotherapy. Yet, in many patients the NK cell compartment is compromised thus lowering the chances of successful outcomes of many immunotherapies. An overview of mechanisms that can drive NK cell dysfunction and hinder immunotherapy success is provided. Rather than relying on the likely dysfunctional endogenous NK cells to work with immunotherapies, adoptive allogeneic NK cell therapies provide a viable solution to increase response to immunotherapies. This review highlights the advances made in development of NK cell therapeutics for clinical application with evidence supporting their combinatorial application with other immune-oncology approaches to improve outcomes of immunotherapies.

\footnotetext{
Keywords: natural killer (NK) cells, NK cells and immunotherapy, NK cells and checkpoint blockade, NK cell crosstalk, immunotherapy resistance, adoptive NK cell therapy, immuno-oncology combinations, NK cell dysfunction
}

\section{INTRODUCTION}

Cancer immunotherapy is a rapidly evolving treatment modality that works by augmenting the body's own immune system. The dramatic successes of cancer immunotherapies have led to a paradigm shift in oncology $(1,2)$. While various immune stimulation strategies such as checkpoint blockade of PD-1/PD-L1 or CTLA-4 have been a major step forward leading to durable responses even in patients with advanced cancers, the overall response rate is low. Responses to anti-PD-1/PDL1 therapies were shown to correlate with expression of PD-L1 on tumors and with preexistence of inflamed ("hot") tumors infiltrated with functional cytotoxic lymphocytes, which accounts for a 
minority of patients $(3,4)$. While the application of immune checkpoint inhibitors is known to mount the potent antitumor response by cytotoxic $\mathrm{T}$ cells, there is a robust body of science suggesting that immune responses independent of cytotoxic $\mathrm{T}$ cells also play critical roles in the efficacy of immunotherapeutic interventions.

Natural Killer (NK) cells are a small subpopulation of lymphocytes that are a part of the innate immune response and are key effectors of immunosurveillance and immunoregulation. NK cells are the first responders of the immune system and have an inherent ability to recognize and lyse virally-infected, stressed, or cancerous cells without prior sensitization or antigen presentation (Figure 1). NK cells perform this differential surveillance of malignant or compromised cells from normal "self" cells through the balance of signaling from surface activating receptors [e.g. NKG2D, natural cytotoxicity receptors (NCRs), 2B4, DNAM-1, activating killer cell immunoglobulin like receptors (KIRs)] and inhibitory receptors (e.g. inhibitory KIRs, NKG2A) that recognize a large repertoire of up- or downregulated molecules including major histocompatibility complex (MHC) class I chain-related proteins A and B molecules, and human leukocyte antigens (HLAs), nectin family proteins such as PVR and many others. The NK cell cytotoxic response is triggered when the activating signals are in excess of inhibitory signals (8). They also express the FcyRIII receptor (CD16) that recognizes antibodies to specific tumor antigens and triggers antibodydependent cell-mediated cytotoxicity (ADCC) (Figure 1). Thus, rather than searching for one unique antigen on a target cell as the T cells do, NK cells recognize patterns of expression indicative of transformation into malignant cells. This broad recognition allows NK cells to preferentially kill tumor cells over healthy tissue without the need for prior training and without being dependent on one unique molecule that when downregulated could lead to a tumor escape from NK cell killing.

Cytotoxicity by $\mathrm{NK}$ cells is carried out by releasing cytoplasmic granules containing perforin and granzymes. However, NK cells not only directly kill compromised cells, but when properly activated, can be potent producers of TNF- $\alpha$ and IFN- $\gamma$, the last one being a known inducer of PD-L1 expression. Alternative mechanisms by which NK cells were shown to carry out their anti-tumor function involve expression of death receptor ligands FasL and/or TRAIL (9-12) and release of extracellular vesicles, such as exosomes, with cytotoxic activity (13) that contain effector miRNAs [reviewed in (14)], cytokines, and display NK cell surface receptors (15-17). In addition to direct killing, NK cells secrete chemokines and cytokines to recruit and coordinate responses by other immune cells, such as $\mathrm{T}$ cells (7) and dendritic cells (DCs), in the tumor microenvironment or site of infection and can prime the adaptive immune response for better viral or tumor control (5-7, 18-23) [reviewed in (24)] (Figure 1).

Recent studies have highlighted the importance of functional NK cells for the success of immunotherapies, including a critical role in successful PD-1/PD-L1 blockade treatment $(25,26)$. For example, presence of NK gene signatures defined by GNLY, KLRC3, KLRD1, KLRF1, NCR1 genes correlated with FLT3LG levels and presence of BDCA- $3^{+}$stimulatory DCs along with improved overall patient survival in all cancer types examined (6). Furthermore, in melanoma patients this study found NK cell frequency correlated with response to anti-PD-1 treatment and improved overall survival while no correlation was found for Treg cells, $\mathrm{CD}^{+} \mathrm{T}_{\mathrm{H}}$ cells, $\mathrm{CD} 8^{+} \mathrm{T}$ cells and $\mathrm{PD} 1^{+} \mathrm{CTLA}^{+} \mathrm{T}$ cells (6). Similar correlation between higher density of intratumoral NK cells and response to therapy was found in a study of 25 patients with metastatic melanoma treated with anti-PD-1 (27). Studies examining the mechanisms of action of checkpoint inhibitors in humans and mice have shed light on the complex interface between the innate and adaptive immune responses, expanding the traditional NK cell functional domain. NK cells join DCs and not only bridge but rather orchestrate the innate and adaptive immunity. NK cells hold a distinct role in potentiating the innate immune response and activating the adaptive immune system through the secretion of proinflammatory cytokines and chemokines, including regulating $\mathrm{T}$ cell responses. NK cells can directly affect T cells by cell-to-cell contact, and indirectly by secretion of cytokines or by recruitment of DCs and modulation of antigen-presenting cells. NK cells can target activated $\mathrm{T}$ cells for elimination and promote differentiation of naïve CD4 T cells [reviewed in (28)].

Most cancer patients have NK cells that are dysfunctional or low in frequency and are further negatively impacted by surgery and standard chemotherapy treatments (29) [reviewed in (30)]. For example, dysfunction of NK cells can be caused by induction of the glycolysis-inhibiting enzyme fructose-bisphosphatase 1 (FBP1) which leads to tumor progression in KRAS-driven models of lung cancer (31). In this model at later stages, tumor growth could only be slowed by transfer of functional NK cells. Additionally, dysfunctional NK cell response can be caused by altered make up of proteins expressed on surface of tumor cells (31-34). For example, it was shown that radiation increased the expression of PD-L1 but decreased expression of activating ligands for NKG2D NK cell receptor through IL-6-MEK/ERK signaling in non-small cell lung cancer (NSCLC) cell lines, protecting the tumor cells from NK cell cytotoxicity (32). Thus, the lack of functional NK cells and/or effective NK cell response may be a potential cause behind the limited response to immunotherapies or other targeted therapies (e.g. therapeutic antibodies) that rely on NK cells for efficacy (31-34). To address this, adoptive NK cells therapies could provide a viable solution to increase response to immunotherapies $(35,36)$. Over the past decade advancements have been made to generate highly cytotoxic NK cells as an "off-the-shelf" cell therapy treatment that have the potential to mount a functional response in the setting of altered tumor environment that poses a critical barrier for endogenous NK cells. These cells can be further modified to enhance their targeting (e.g., with chimeric antigen receptors) and decrease their sensitivity to tumor immunosuppression (e.g. NKG2A knock-out). Thus, appropriate NK cell-based therapeutics could be effectively applied with immunotherapies to increase response rates and duration.

This review highlights the importance of the early actions of the NK cell response and the pivotal role NK cells hold in 


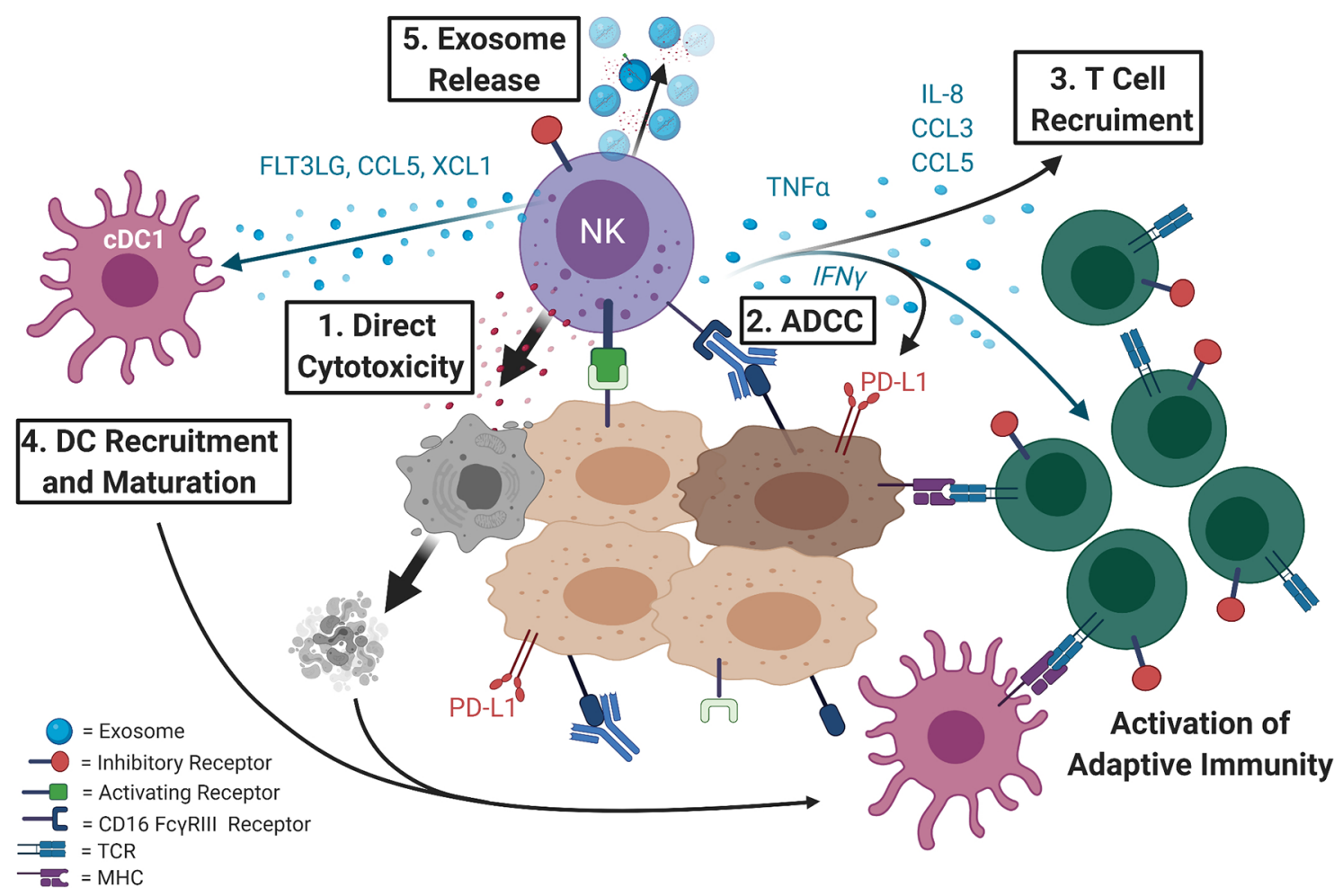

FIGURE 1 | NK cells are key effectors of anti-tumor response and direct both the innate and the adaptive arms of the immune system. 1) NK cells are the first responders of the immune system and can directly recognize and lyse tumor cells. Activating receptors on NK cells recognize ligands that are mostly expressed on compromised cells while inhibitory receptors bind to self-ligands that mark healthy, normal cells. 2) NK cells also express the CD16 FcyRIII receptor that binds antibodies and triggers antibody-dependent cellular cytotoxicity (ADCC). This response contributes to efficacy of many of the antibody-based cancer therapeutics (e.g. Herceptin or Erbitux). 3) NK cells not only directly lyse compromised cells causing release of tumor antigens, but when activated release cytokines such as TNF- $\alpha$ and IFN- $\gamma$, the later known to induce PD-L1 expression, that can recruit other immune cells and inflame or "heat up" the tumor microenvironment priming it for immunotherapy. 4) Intratumoral NK cells produce chemoattractants CCL5 and XCL1 (5) as well as FLT3LG, the formative cytokine of rare intratumoral stimulatory dendritic cells ( $C D C 1)(6)$ that can activate the adaptive immune response. NK cells have also been shown to directly recruit T cells by releasing cytokines such as IL-8, CCL3, and CCL5 (7). 5) Additionally, NK cells can release exosomes with cytotoxic activity and can contain effector miRNAs, cytokines, and display NK cell surface receptors.

priming the immune system and setting the stage for successful response to cancer immunotherapy with focus on approved immunotherapies or those in late-stage clinical trials. The mechanisms that can drive NK cell dysfunction are reviewed with the intent to demonstrate how this can negatively impact subsequent immunotherapy response and how there is a need for prospective studies with focus on the role of NK cell compartment in immunotherapeutic response. The last part will highlight the advancements in NK cell therapeutics and how NK cell-based therapeutics can provide a viable solution to increase success of most immunotherapeutic therapies (and beyond).

\section{NK CELLS AND IMMUNE CHECKPOINT INHIBITION}

The success of monoclonal antibodies targeted to block immune regulatory checkpoint receptors or ligands has shifted immune checkpoint inhibitors and immunotherapy to the forefront of oncology [reviewed in (37)]. A Phase III clinical trial (NCT01866319) of the checkpoint inhibitor Pembrolizumab (anti-PD-1) produced overall response rates (ORR) in 33\% of patients with advanced-stage melanoma (38). Since then, Pembrolizumab has been indicated for the treatment of twenty cancer types (39) and a search of the NCT database using the keyword 'Pembrolizumab' showed over 100 Phase III or IV interventional clinical trials that are currently active determining the efficacy of Pembrolizumab in more cancer types and in combination therapies. Although there are reports of durable objective response rates for many patients, the overall response rates are still low, and many patients eventually relapse. For example, in the ongoing Phase IB clinical trial NCT02054806 studying the efficacy of pembrolizumab in patients with advanced solid tumors, while treatment of patients with some tumor types have resulted in preliminary overall response rates over $30 \%$, most are much lower (40-42). Preliminary results from NCT02054806 and the completed Phase 1 Clinical Trial 
NCT01848834, showed Pembrolizumab treatment of patients with colorectal cancer resulted in ORR of only $4.3 \%$ (43), while for patients with triple negative breast cancer, head and neck squamous cell cancer, gastric cancer, and urothelial carcinoma the ORR were between $15.6 \%$ and $21.2 \%$ (40, 44-47). Thus, the scope of the clinical success of immune checkpoint blockade therapies is limited to a select subset of patients typically with cancers expressing high levels of PD-L1 and infiltrated with lymphocytes. Current strategies have focused on combination therapies with PD-1 checkpoint inhibitors, and in fact over 3000 clinical trials are ongoing (48). Many of these combination therapies are showing success. For example, the PD-L1 inhibitor Atezolizumab plus Tiragolumab, an anti-TIGIT antibody (TIGIT is a highly expressed receptor both on T cells and NK cells) has shown early clinical activity with on ORR of $46 \%$ in patient with advanced solid tumors and is currently in phase I clinical trials (49). Many checkpoint inhibitor combinations have failed as well. Understanding mechanistically the variables contributing to the heterogeneity of response to checkpoint blockade is necessary for better rational design of these therapies in order to increase efficacy of combination therapies and to achieve more widespread responses and/or longer response duration.

Current strategies to improve immune checkpoint blockade therapies predominantly focus on cytotoxic $\mathrm{CD}^{+} \mathrm{T}$ cells, however emerging evidence suggests contributions from other immune cells to the efficacy of checkpoint inhibitors. Many cancer types have adopted mechanisms to suppress and evade detection by the immune system, commonly through the loss of major histocompatibility complex (MHC) molecules or depressed neoantigen load [reviewed in (50)]. While down regulation of $\mathrm{MHC}$ expression may render tumors camouflaged from detection and lysis by $\mathrm{CD}^{+} \mathrm{T}$ cells, tumors that express high levels of PD-L1, even with lower MHC expression, are still responsive to PD-1/PD-L1 blockade (51, 52). These findings challenge the prevailing view that $T$ cells are the exclusive mediators of the anti-tumor response and suggest the involvement of other immune cell populations that are also unleashed by PD-1 blockade and provide a critical support for the overall success of the treatment. Recent studies have supported this idea that multiple effector cell populations, including NK cells, are impacted by immune checkpoint inhibition and treatment efficacy hinges on the collective contributions of these populations $(53,54)$ [reviewed in (55) and (56)].

NK cells share similar effector functions and roles as cytotoxic $\mathrm{T}$ cells but are able to direct the immune response towards resistant tumor cell populations. Contrary to $\mathrm{CD}^{+} \mathrm{T}$ cells, loss of MHC removes inhibitory interaction with KIRs on NK cells and thus makes tumor cells more susceptible to lysis by NK cells. Thus, NK cells have shown to be uniquely capable of targeting highly aggressive cancer stem-like cells and undifferentiated tumors, which are highly refractory to chemotherapy. In addition, NK cells are capable of catalyzing differentiation of tumor cells via secreted and membrane-bound IFN- $\gamma$ (57). Differentiation prompts remodeling of the surface receptor profile - an increase in MHC class I and CD54 and decrease in CD44 expression - and reins in tumor growth and metastasis (58). These differentiated tumors should be also better targets for $\mathrm{T}$ cell recognition and elimination. NK cells have been shown to selectively target senescent tumor cells. A study led by Ruscetti et al. determined that the observed reduced proliferative capacity of KRAS-mutant lung tumors in mice treated with a cytostatic drug regimen resulted primarily from the natural senolytic activities of NK cells (59). Although NK cells have been less heavily studied in the context of checkpoint blockade, current evidence supports NK cells involvement and impact on the response to immunotherapy.

\section{NK Cells in PD-1/PD-L1 Checkpoint Blockade}

The presence of PD-L1 in tumors has been shown to be a predictor of tumor response to PD-1/PD-L1 checkpoint blockade and NK cells have an intricate interplay with the PD1/PD-L1 axis. NK cells have been shown to increase PD-L1 expression on tumor cells, express PD-L1 and PD-1 in some contexts and be directly inhibited by interaction with PD-L1 positive tumors or indirectly by changes in the tumor milieu in response to PD-L1 induction. Additionally, blockade of the PD1/PD-L1 axis have been shown to increase NK cells anti-tumor response. This is summarized in Figure $\mathbf{2}$ and discussed in detail below.

Melanoma patients who responded to anti-PD-1 therapy had higher intratumoral and peritumoral NK cell densities, and these NK cells had increased cytotoxic signatures of elevated CD16 expression and granzyme B versus NK cells in non-responders (27). Activated NK cells are a major source of IFN- $\gamma$, which drives cancer-induced inflammation and leads to induction of PD-L1 expression on tumor cells. As an example, particle activated NK cells (PM21-NK cells) were shown to induce PDL1 on tumors both in vitro and in vivo (63). Presence of PD-L1 on tumors has been so far the most reliable marker of treatment response (64) and is used for patient selection for treatment of NSCLC. Presence of PD-L1 expression on tumors is typically associated with improved response to anti-PD-1/PD-L1 treatment $(65,66)$. In fact, Avelumab failed to show survival advantage over docetaxel in patients with platinum treated NSCLC when all patients (i.e., with PD-L1 tumor expression of $\geq 1 \%$ ) were included but survival advantage was observed in exploratory analysis when patients were stratified based on PDL1 expression on their tumors (65). Median survival was 10.5 months (95\% CI 9.2-12.9) in the entire Avelumab group with the PD-L1 $\geq 1 \%$ versus 9.9 months (8.1-11.8) in the docetaxel group, but in stratified analysis of the Avelumab group median survival was 13.6 (10.1-18.5) when PD-L1 expression cutoff was set to $\geq 50 \%$ and $17.1(10.6-25.0)$ with cutoff of $\geq 80 \%$ (67). NK cells as the first responders are likely one of the main populations that drives the induction of PD-L1 on tumors yet, as will be discussed in detail in later section, are frequently dysfunctional in cancer patients. Adoptive transfer of activated NK cells with high IFN- $\gamma$ could potentially improve response to $\mathrm{PD}-1 / \mathrm{PD}-\mathrm{L} 1$ blockade via induction of PD-L1. 
As described above PD-L1 ${ }^{+}$tumors show favorable responses to PD-L1 blockade, however responses were also observed for patients with tumors lacking PD-L1 expression $(68,69)$. PD-L1 can be expressed on cells other than tumors including on immune cells such as e.g. dendritic cells or myeloid derived suppressor cells within the tumor microenvironment and thus inhibiting anti-tumor response by effector immune cells (70). Anti-PD-1/PD-L1 treatment can lead to reactivation of inhibited effector cells with subsequent IFN- $\gamma$ secretion as a result of an anti-tumor response (71) and likely induction of PD-L1 on initially $\mathrm{PD}-\mathrm{L1}^{-}$tumor cells. Recent publication by Dong et al. identified $\mathrm{PD}-\mathrm{L}^{+}{ }^{+} \mathrm{NK}$ cells as the cytolytic effector cell population that may provide alternative explanation to the efficacy of anti-PD-L1 antibody therapy in these settings where tumors lack PD-L1. PD-L1 expression is inducible on activated NK cells through direct interaction with tumor cells via the p38/ $\mathrm{NF}-\kappa \mathrm{B}$ pathway and by stimulation with cytokines IL-12 and IL18 (25). In vitro, $\mathrm{PD}-\mathrm{L1}^{+} \mathrm{NK}$ cells display heightened cytotoxicity compared to their $\mathrm{PD}-\mathrm{L1}^{-}$counterparts which is further enhanced by engagement with anti-PD-L1 antibodies. In response to anti-PD-L1 treatment with Atezolizumab, mice engrafted with human NK cells and PD-L1' K562 myeloid leukemia cells demonstrated significantly elevated levels of granzyme B, IFN- $\gamma$, and CD107a, contributing to notable reductions in tumor burden and significant improvement in survival over the placebo controls (25). Survival advantages were

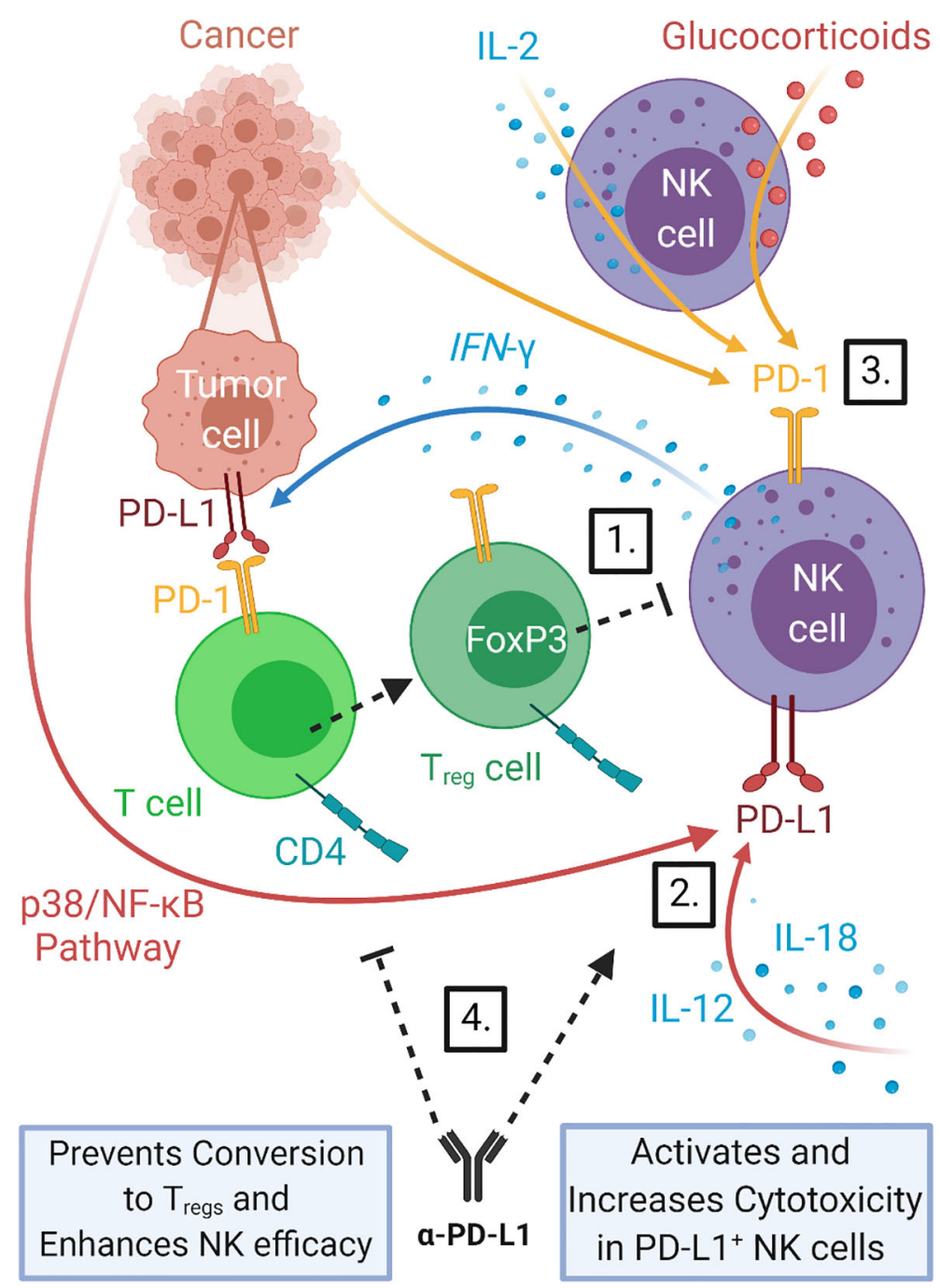

FIGURE 2 | NK cells interact with the PD-1/PD-L1 immune checkpoint axis. NK cells can increase the expression of PD-L1 on tumor cells through release of cytokines such as IFN- $\gamma$, promoting PD-1/PD-L1 driven stimulation of Treg production which in turn can inhibit NK cell function. 1) NK cells have also been shown to express both PD-L1 and PD-1 themselves. PD-L1 expression can be induced in NK cells by direct interaction with tumor cells via the p38/NF-kB pathway and by stimulation with cytokines IL-12 and IL-18 (25). 2) PD-1 expression in NK cells has been shown to be upregulated in a variety of cancers (26, 60, 61) and to be inducible in response to IL-2 stimulation (60) and glucocorticoid signaling (62). 3) Treatment with PD-1/PD-L1 blockade therapy can help prevent Treg inhibition of NK cells and counteract PD-1/PD-L1 driven NK cell dysfunction. 4) PD-L1 expression on tumors correlates with response to PD-1/PD-L1 checkpoint blockade therapies, thus induction of PD-L1 by NK cells should improve outcomes of this treatment. 
lost both in mice lacking PD-L1 ${ }^{+} \mathrm{NK}$ cells and in NK celldepleted mice. Congruent with the above findings, acute myeloid leukemia (AML) patients who achieved complete remission were found to have a higher proportion of $\mathrm{PD}-\mathrm{L1}^{+} \mathrm{NK}$ cells at complete remission compared to at the time of diagnosis as well as compared to AML patients who failed to reach complete remission (25). Taken collectively, these studies suggest the PD-L1 status of NK cells should be an important consideration in determining the efficacy of $\mathrm{PD}-1 / \mathrm{PD}-\mathrm{L} 1$ checkpoint blockade therapy.

Effector cells such as T cells have been shown to benefit from checkpoint blockade through the inhibition of the PD-L1 receptor PD-1 on their surface. NK cells isolated from healthy donors do not constitutively express PD-1, however PD-1 expression is inducible in response to IL-2 stimulation (60) and glucocorticoid signaling in the stress response has been linked to PD-1 upregulation on NK cells (62). PD-1 has also been found to be upregulated on activated NK cells in a variety of cancers with mean expression levels ranging widely from $9 \%$ to $64 \%$ dependent on the cancer setting $(26,60,61)$. Yet, PD-1 expression on NK cells appears to be context dependent and thus different observations were made dependent on the experimental conditions used. A recent study that extensively examined the PD-1 expression on NK cells from human and mouse in context of tumor and viral models found that as opposed to T cells, NK cells mostly lacked PD-1 expression arguing for a more indirect interaction with the PD-1/PD-L1 axis (72). More in-depth studies on the mechanisms regulating $\mathrm{PD}-1$ receptor expression on NK cells are needed.

The presence of PD-1 on NK cells affects their function. While PD-1 expression on NK cells can initially activate them, it drives expression of PD-L1 on tumor cells which can lead to NK cell exhaustion. $\mathrm{PD}-1^{+}$murine $\mathrm{NK}$ cells compared to PD-1 murine NK cells demonstrate an activated signature, characterized by expression of NK cell activation markers SCA-1 and CD69, CD107a expression, and intracellular accumulation of IFN- $\gamma$ after tumor engagement (26). However, PD-L1 ligation leads to dysfunction of IL-2-activated PD- $1^{+} \mathrm{NK}$ cells, marked by blanket downregulation of CD16 and CD107a (61), transitioning NK cells from an activated to exhausted phenotype. To combat this, immunomodulation via the PD-1/ PD-L1 axis checkpoint inhibitor Nivolumab was shown to restore cytotoxicity of $\mathrm{PD}-1^{+} \mathrm{NK}$ cells co-cultured with tumors expressing high levels of PD-L1 $(27,61)$ and reestablish the IFN- $\gamma$ response of NK cells (61). Restoration of NK cell faculties correspond with improved clinical outcomes in head and neck cancer patients (61).

As suggested earlier, even in context where NK cells lack PD-1 or PD-L1 expression, checkpoint inhibitors can also indirectly influence anti-tumor NK cell functions through the modulation of other immune cell populations $(63,73)$ (Figure 2). Crosstalk between $\mathrm{CD}^{+} \mathrm{T}$ cells and NK cells is requisite for optimal NK cell activity. $\mathrm{CD}^{+} \mathrm{T}$ cells activate NK cell function two-fold: directly through the secretion of stimulatory IL-2, and indirectly by stimulating antigen presenting cells to secrete IL-12, with both cytokines working synergistically to positively regulate IFN- $\gamma$ production by NK cells. The importance of $\mathrm{CD}^{+} \mathrm{T}$ cell/NK cell interaction is highlighted by the observed correlation between $\mathrm{CD} 4^{+}$ $\mathrm{T}$ cell exhaustion in chronic infections and impaired NK cellmediated lysis of target cells (74). PD-1 signaling on $\mathrm{T}$ cells is independently capable of converting $\mathrm{CD}^{+} \mathrm{T}$ helper cells into regulatory $\mathrm{T}$ cells (Tregs) by inducing Foxp3, a transcription factor that drives this conversion and is critical in the maintenance of immunosuppressive Treg functions $(75,76)$. Surface expression of transforming growth factor beta 1 (TGF- $\beta$ ) on $\mathrm{CD}^{+} \mathrm{CD}^{+} 5^{+} \mathrm{Foxp}^{+}$Tregs controls the expression of key NK cell activation receptors - NKp30, NKG2D, and CD16 (77-80)and neutralizes the potent anti-tumor NK cell response. There is a dual effect amplifying the negative impact of PD-L1 on NK cells whereby expanded Tregs directly inhibit NK cells and also their expansion depletes $\mathrm{CD}^{+} \mathrm{T}$ cells and thus diminishes the positive effects of $\mathrm{CD}^{+} \mathrm{T}$ helper cells on NK cell function. PD-1/PD-L1 blockade indirectly offers improved NK cell survival and function by preventing the expansion and persistence of inhibitory Tregs in the tumor microenvironment (63) and potentially by mitigating $\mathrm{CD} 4^{+}$ T helper cell exhaustion. Accordingly, PD-L1 blockade enhanced anti-tumor efficacy of expanded PD- $1^{-} \mathrm{NK}$ cells that were previously otherwise unaffected by anti-PD-L1 treatment in vitro. $\mathrm{CD} 4^{+} \mathrm{T}$ cell exhaustion is mediated dually by IL-10 and the PD-1. In the context of an HIV infection, combined blockade of the PD-1 and IL-10 pathways reinvigorates $\mathrm{CD} 4^{+} \mathrm{T}$ cell effector functions, resuming $\mathrm{NK}$ cell degranulation and cytolysis (74). This strategy of immunomodulation boosting $\mathrm{CD}^{+} / \mathrm{NK}$ cell cooperativity may prove beneficial in cancer therapy. Sequestration of IL-2 by Tregs via their high-affinity IL-2R receptor is an alternative mechanism by which Tregs weaken NK cell anti-tumor activities (81). Various strategies to engineer recombinant human IL-2 that is biased toward low-affinity IL-2 receptors present on $\mathrm{NK}$ and $\mathrm{CD}^{+} \mathrm{T}$ cells in efforts to mitigate Treg-driven immunosuppression have been developed (82-84). They are currently being tested in Phase I and II clinical trials after yielding promising results in murine models, both alone and as combination partners for checkpoint inhibitors in cancer therapy (82-84).

Rejuvenation of impaired NK cell activity holds broader implications regarding the immune response as NK cells are involved in the priming of the adaptive immune system via recruitment of other immune cells, such as DCs. NK-DC crosstalk is an important interaction involved the innate immune response. Cross-talk between NK and DC cells leads to DC maturation and NK cell activation. NK cells release IFN- $\gamma$ and TNF $\alpha$ which promote DC maturation (85). In turn mature DCs can secrete cytokines such as IL-12 and IL-15 that stimulate NK cell proliferation and survival and IFN- $\gamma$ production $(85,86)$. Activated NK cells also have the ability to kill DCs that do not properly mature by engagement of the activating receptor NKp30, term DC editing (87). DC-NK cross-talk is an important player in the immune response to tumors and should be considered in evaluating the effects of cancer immunotherapy. This topic has been widely investigated in recent years, see $(24,88)$ for a review of this topic. Conventional type 1 dendritic cells (cDC1) serve in crosspriming $\mathrm{T}$ cells in tumor-draining lymph nodes through the 
secretion of chemo- and cytokines regulating $\mathrm{T}$ cell survival, effector functions, and their trafficking to the tumor microenvironment. The importance of $\mathrm{cDC1}$ in oncologic immunity is highlighted by the abolishment of tumor rejection and responsiveness to adoptive $\mathrm{T}$ cell therapy and immune checkpoint blockade in mice lacking $\operatorname{cDC} 1(89,90)$ and it has been shown that induction and activation of tumor-residing cDC1s can help overcome resistance to anti-PD-L1 therapy (91). Activated NK cells are paramount in producing cDC1 chemoattractants and mobilizing them to the tumor microenvironment, which in turn recruit $\mathrm{T}$ effector cells and launch the adaptive immune response (5) (Figure 1). Increased presence of both $\mathrm{NK}$ and intratumoral $\mathrm{CDC1}$ cell populations, and not $\mathrm{T}$ cells, in the tumor microenvironment was a predictive biomarker of tumor responsiveness to anti-PD-1 immunotherapy and prolonged overall survival in melanoma patients (6). In support of this, new evidence challenges the widely accepted theory that PD-1 blockade reinvigorates preexisting, exhausted, tumor-infiltrating $\mathrm{T}$ cells and suggests that de novo recruitment of $\mathrm{T}$ cells is the main mechanism of $\mathrm{PD}-1$ blockade. Comparing single-cell RNA sequencing and $\mathrm{T}$ cell receptor (TCR) sequencing data of tumor-infiltrating $\mathrm{T}$ cells before and after PD-1 blockade in patients with basal cell or squamous cell carcinoma, Yost et al. found that tumorinfiltrating TCR clones present prior to administration of PD-1 blockade are neither activated nor enriched in the tumor microenvironment following treatment (92). Rather, the prevailing $\mathrm{T}$ cell population present post-treatment expresses novel TCR specificities not identified in the pre-treatment tumor sample, suggesting anti-PD-1 therapy does not reactivate existing exhausted tumor-infiltrating $\mathrm{T}$ cells, but rather recruits new, activated $\mathrm{T}$ cells from the peripheral blood to the tumor (92). Given the seminal role NK cells hold in directing the adaptive immune response outlined above, it is likely NK cells are responsible for the recruitment of novel $\mathrm{T}$ cells to the tumor microenvironment. Verification of this hypothesis in future studies would add to the evidence that NK cells are important early organizers of the body's anti-tumor response.

Collectively, these findings provide evidence that PD-1 is an important checkpoint in NK cell activation acting upon NK cells via multiple direct and indirect mechanisms summarized in Figure 2 and that PD-1/PD-L1 immunotherapy not only revives NK cell-mediated lysis of tumor cells and cytokine production, but concurrently supports the NK cell-directed priming and recruitment of the adaptive immune response. Thus, addition of adoptive NK cell therapy to treatments targeting $\mathrm{PD}-1 / \mathrm{PD}-\mathrm{L} 1$ axis has the potential to improve outcomes. In support of this, results from a completed Phase II clinical trial of combination PD-1 inhibitor Pembrolizumab and allogeneic ex vivo expanded NK cells showed significant improvement of survival of patients with previously treated advanced NSCLCs that received combination therapy as compared to Pembrolizumab alone (93). Phase I/IIa clinical trial (NCT03937895) for combination therapy of allogenic NK cells and Pembrolizumab is ongoing for treatment of biliary tract cancer.

\section{NK Cells in CTLA-4 Checkpoint Blockade}

Another breakthrough checkpoint therapy relies on targeting the CTLA-4 molecule, also known as CD152. Ipilimumab is a highly successful antibody against CTLA-4 approved by the FDA for treatment of melanoma [reviewed in (94)] and for combination therapy with Nivolumab (anti-PD-1) for advanced renal cell carcinoma, MSI-H/dMMR metastatic colorectal cancer, hepatocellular carcinoma, metastatic NSCLC, and malignant pleural mesothelioma (95) [reviewed in (96)]. CTLA-4 is an inhibitory receptor constitutively expressed in Tregs and upregulated in activated $\mathrm{T}$ cells. Stojanovic et al. found that CTLA-4 and the T cell activating receptor CD28 also regulate the NK cell response in mice (97). CD28 and CTLA-4 are found to be upregulated in murine NK cells in response to IL-2 activation (97). These receptors work antagonistically to regulate IFN- $\gamma$ production by NK cells: CD28 promoting IFN- $\gamma$ synthesis while CTLA-4 suppresses it.

A correlation between higher frequencies of CTLA $-4^{+}$Tregs in the tumor microenvironment and abrogated $\mathrm{NK}$ cell activation and cytotoxicity in head and neck cancer patients treated with Cetuximab (anti-EGFR) was reported by Jie et al. (98). Anti-CTLA-4 pathway blockade mediates selective depletion of CTLA $-4^{+}$tumor-infiltrating Tregs and could therefore indirectly rescue NK cells from Treg suppression. This evinces that NK cells are also potential targets of CTLA-4 blockade (99). Anti-CTLA-4 was effective in eliminating intratumoral Tregs and initiating the recovery of NK cell ADCC following Treg suppression (98, 100). Combinatorial administration of anti-CTLA-4 with IL-2Cx, a complex of IL-2/anti-IL-2 which directs IL-2 to NK and $\mathrm{CD}^{+}{ }^{+} \mathrm{T}$ cells but not Tregs, or IL-15/IL-15Ralpha complexes further tips the tumoral effector/regulatory cell ratio in favor of activated NK cells and enhances tumor control $(82,101)$. A Phase I clinical trial (NCT04290546) is ongoing to evaluate combination therapy of Ipilimumab, IL-15 superagonist N-803, and adoptive NK infusion for head and neck cancer.

\section{NK Cells in NKG2A Blockade}

As opposed to PD-1 and CTLA-4, the inhibitory NKG2A receptor is expressed predominately on $\mathrm{NK}$ cells and a select subset of $\mathrm{CD}^{+} \mathrm{T}$ cells has also been identified as a prospective target for this checkpoint blockade. Engagement of human leukocyte antigen-E (HLA-E) by the NKG2A receptor sends a strong signal inhibiting NK cell-mediated lysis of the target cell (102). Upregulation of the NKG2A ligand, HLA-E, by malignant cells in response to IFN- $\gamma$ secreted by tumor-reactive immune cells is a common mechanism by which tumors thwart NK cell surveillance (103). NKG2A signaling blockade or downregulation of NKG2A receptor expression should bypass HLA-E-induced NK cell inhibition and restore normal NK cell function. In vitro studies showed anti-NKG2A Monalizumab treatment prompts increased CD107a expression, a marker for activated NK cells, and IFN- $\gamma$ production by IL- 2 activated NK cells and $\mathrm{CD}^{+} \mathrm{T}$ cells, yielding significant improvements in tumor growth control and prognosis (104). The beneficial effects observed with anti-NKG2A blockade are magnified when used in 
conjunction with anti-PD-1 Durvalumab (104). Furthermore, combining anti-NKG2A Monalizumab with anti-EGFR Cetuximab was shown to promote ADCC, evidenced by the higher density of CD137 activation markers on NK cells (104).

Two recent studies that used engineered NK cells lacking functional NKG2A underscore that NKG2A is a critical inhibitor of $\mathrm{NK}$ cell responses, and an important target for immunotherapies. A new study by Berrien-Elliott et al. has shown NKG2A is transcriptionally induced in cytokineinduced memory-like NK (CIML NK) cellular therapy and a dominant checkpoint, but not in conventional NK cell antitumor response (105). Anti-NKG2A treatment or NKG2A knock-out returned CIML NK IFN-y production and response to HLA-E+ K562 cells. NKG2A blockade or elimination also restored CIML NK cell anti-leukemia response. Secondly, Kamiya et al. (106). engineered NK cells to express singlechain variable fragment from an anti-NKG2A antibody linked to an endoplasmic reticulum-retention domain (106). This approach prevents nascent NKG2A from migrating out of the endoplasmic reticulum, effectively blocking its de novo expression. Experiments using immunodeficient mice engrafted with Ewing's sarcoma or osteosarcoma cell lines transduced with HLA-E found that the majority of immunodeficient mice receiving NKG2Anull NK cell infusions achieved long-term survival, with the median overall survival exceeding 269 days following Ewing's sarcoma injection and median survival not reached after 60 days follow-up for osteosarcoma injection (106). Control NK cells only delayed tumor development with median survivals of less than 40 days (106). These two studies highlight the importance of NKG2A blockade and present this $\mathrm{NK}$ inhibitory receptor as an important target for future immunotherapeutics. In fact, the safety and efficacy of adjunct therapy combining Monalizumab with Cetuximab is currently being assessed in a Phase II clinical trial (NCT02643550) in patients with recurrent or metastatic squamous cell carcinoma of the head and neck.

\section{Other Checkpoints}

Many therapeutics targeting other immune checkpoint are being developed and evaluated clinically and are reviewed elsewhere. Some of these checkpoints are highly expressed on NK cells such as IL-1R8, TIGIT, TIM-3, and KIRs and the efficacy of therapies targeting these molecules will depend on the functional state of NK cells. Future studies to evaluate combination therapy of these inhibitors with adoptive NK cell transfer could provide methods for enhanced cancer treatment and tumor control. The role adoptive NK therapy plays in the use of checkpoint inhibitors is summarized in Figure 3A.

\section{NK CELLS AND ONCOLYTIC VIRUSES}

Oncolytic viruses (OVs) are a novel class of drugs that are rapidly gaining traction in cancer treatment. Exploiting cancer cells' defective antiviral defenses, viral replication within cancer cells causes cell lysis. In 2015, the field marked a major milestone with the first FDA-approved oncolytic virus, Talimogene laherparepvec, a modified type I herpes simplex virus, for treatment of advanced melanoma [reviewed in (108)]. Numerous other clinical trials are currently ongoing. Initially therapeutic efficacy of OVs was thought to be derived solely from the direct killing of tumor cells. Now, the field recognizes a split mechanism of OV action: in addition to direct lysis of cancer cells, induction of the adaptive and innate immune system by OVs largely contributes to the observed efficacy of OV agents, questioning the previously held belief that pre-existing antiviral immunity poses a major impediment to this treatment modality. Moving forward, a better understanding of the interplay between the established immune system and OVs is necessary to optimize antitumor immunity and improve therapeutic interventions.

In addition to their role in oncolysis, OVs prime the immune system to overcome the suppressive pressures of the tumor microenvironment. Fujihara et al. show that intratumoral injection of an inactivated Sendai virus (hemagglutinating virus of Japan-Envelope; HVJ-E) in mice enhanced local production of the IFN-inducible chemokine CXCL10 by DCs, which promoted intratumoral trafficking of activated IFN- $\gamma$-secreting NK cells and led to a reduction in renal cell carcinoma growth (109). In a follow up mouse study, systemic administration of IL-12conjugated HVJ-E was found to further appreciate regional IFN- $\gamma$ production and the magnitude of cytotoxic $\mathrm{T}$ lymphocyte activation (110). The resultant recruitment of activated innate and adaptive lymphocytes into the tumor milieu due to OV-mediated inflammation transitioned immunologically "cold" tumors into "hot" tumors that are responsive to immunotherapy. Conditioning of the tumor microenvironment and immune system reveals a significant corollary of therapeutic delivery of OVs and provides the rationale behind adjuvant oncolytic virotherapy.

NK cells are potentially a clinically relevant determinant of the therapeutic efficacy of oncolytic virotherapy. In a recent report by Leung et al. NK cells show contact-dependent activation and anti-cancer cytotoxicity against adenovirusinfected ovarian cancer cells (111). The immune system activation cascade is set into motion by the antiviral response of the NK cell compartment. In a study by Ricca et al. when testing if pre-existing immunity to Newcastle Disease Virus (NDV) increases the therapeutic efficacy of the oncolytic virus, they found that depletion of $\mathrm{NK}$ cells prior to initial immunization to NDV, decreased the therapeutic efficacy of NDV against tumors and NK cells are likely important for early tumor clearance, and recruitment and activation of CD8 T cells (112). However, given NK cells' dual role in the body's innate defense against malignancies and virally compromised cells, killing of virus-infected cancer cells by NK cells could also limit the extent of viral oncolysis and thus tumor clearance. A mathematical model developed by Kim et al. sheds light on how exogenous NK cell therapy would affect the use of OVs. Using a combination therapy coupling oncolytic herpes simplex virus and bortezomib, a proteasome inhibitor that amplifies viral replication, the model predicts both depletion of endogenous NK cells and injection of exogenous NK cells would yield 
enhanced antitumor efficacy (113). Depletion of endogenous NK cells reduces the friction applied by the antiviral immune response, increasing OV-mediated lysis of tumor cells, whereas, adjuvant injection of exogenous NK cells grants an advantage to the immune system, boosting tumor cell killing by NK cells (114). These predictions were validated in primary glioma mouse models, granting a significant survival advantage to mice receiving either endogenous NK cell depletion or exogenous NK cell injection. The combination of oncolytic measles vaccine virotherapeutics with activated human NK cells led to enhanced sarcoma cell lysis and increased NK activation markers (115) and provides further justification for clinical trials to test this combination therapy. Engineering of NK cells and OVs have also been suggested to further enhance the combinatorial therapeutic potential. Blockade of NK inhibitory receptor TIGIT was shown to increase the activity of adenovirus in ovarian cancer (111). Enhanced efficacy was seen when matching chemokine and receptor were incorporated into NK cells and vaccinia virus (116). CCR5-engineered NK cells combined with CCL5-expressing oncolytic vaccinia virus enhanced NK cell homing and therapeutic effects (116).

Combinations of OVs with other immunotherapies could have enhanced therapeutic benefits. Initial studies evaluating combination $\mathrm{OV}$ and checkpoint blockade therapy in mice generated data that underscores the notion that the therapeutic efficacy of oncolytic virotherapy is primarily contrived from the tumor-specific immune response coordinated by NK cells and carried out by $\mathrm{CD}^{+} \mathrm{T}$ cells, rather than direct virus-mediated lysis. Several pre-clinical studies describe potent therapeutic synergy when OVs and checkpoint inhibitors were administered jointly in mice $(112,117)$. The use of combinatorial $\mathrm{OV}$ and immune checkpoint therapy as well as engineering OVs for delivery of immune checkpoint inhibitors into the intratumoral environment is currently being investigated (118-122). Testing has also progressed to earlyphase clinical trials and early reports remain promising (123, 124). Future research directed at probing the therapeutic variables including the nature of the virus, the checkpoint inhibitor, cancer setting, and dosing regimen and the impact adoptive NK cell therapy could have on these variables, and the identification of response biomarkers are necessary to optimize this multimodal therapy. The interaction between adoptive NK cell therapy and OV treatments is summarized in Figure 3B.

\section{NK CELLS AND STING ACTIVATORS}

Stimulation of interferon genes (STING) is a relatively new immunotherapeutic strategy. STING is a transmembrane protein localized to the endoplasmic reticulum that was first discovered as a cytosolic DNA sensor. Sources of cytosolic DNA can be nuclear, mitochondrial, or exogenous in origin. Tumors have a high incidence of chromosomal instability, driving the formation of micronuclei. These micronuclei can rupture and release DNA into the cytosol. Binding of cytosolic DNA and cyclic guanosine monophosphate (GMP)-adenosine monophosphate (AMP) synthase (cGAS) generates the STINGactivating second messenger cyclic GMP-AMP (cGAMP) (125). STING activation produces $\mathrm{NF}-\mathrm{\kappa B}$ and interferon regulatory factor 3 (IRF3) which induce the transcription of type I IFNs (IFN- $\alpha$ and IFN- $\beta$ ) and other chemokines and cytokines that activate innate immunity $(126,127)$. Recently, STING activation has also demonstrated its essential involvement in priming NK cell-mediated antitumor immune responses. STING is an absolute requirement for the rejection of tumor cells that are sensitive to NK cell lysis and NK cell depletion abolished any STING-mediated protection in mice with RMA-S lymphoma or B16-BL6 melanoma (107). Intriguingly, Marcus et al. also found that cGAS expression by tumor cells, and therefore, tumororiginating cGAMP, is compulsory for STING-dependent tumor rejection (107). Strong relationships were observed between cGAS expression and NKG2D ligands (107). These findings are consistent with data previously reported by Lam and colleagues that activation of the cGAS-STING pathway increases expression of RAE-1 ligands for the activating NKG2D receptor on NK cells (128). Inactivation of cGAS in some tumors may serve as a mechanism of STING-mediated immune escape $(129,130)$ and delivery of exogenous cGAMP or STING agonists may stimulate intrinsic STING signaling, disabling cGAS-deficient tumor-driven immune suppression [reviewed in (131)].

The clinical significance of the cGAS-STING pathway was investigated in a gastric cancer by Song et al. The group observed a positive correlation between low STING expression and several clinical factors including tumor size, TNM stage, and patient survival (132). The group's findings parallel conclusions from Marcus et al. that elevated cGAS expression positively correlated with prolonged survival in melanoma patients $(107,126,127)$. These reports indicate that STING expression may be a useful prognostic tool, further evaluated in multiple tumor types in a recent study by An et al. (133). Moreover, STING agonists may "heat up" tumors, functioning as a precursor to immune checkpoint inhibitor treatment. STING activation catalyzes type I IFN production, stimulating the release of CXCL9 and CXCL10, which, as previously mentioned, draft the prerequisite tumor-infiltrating lymphocytes and precondition the immunological landscape for a robust checkpoint inhibitor-led anticancer response. In pre-clinical studies, intratumoral administration of the STING agonist, ADU-S100 (S100), provoked potent antitumor responses (134-136). Treatment of mice bearing poorly immunogenic B16 tumors with coadministration of S100, anti-PD-1, and anti-CTLA-4 yielded significant increases in IFN- $\gamma$-secreting tumor-specific $\mathrm{T}$ cells and conferred a significant survival benefit over mice receiving single-agent regimens (136). Despite CXCL9 and CXCL10 recruiting both $\mathrm{NK}$ cells and $\mathrm{T}$ cells, these studies predominately examined the antitumor impact of combined STING agonists and immune checkpoint blockade from a $\mathrm{T}$ cell perspective. The contributions of NK cells are often overlooked, however, based on our knowledge of the overlapping immunological niches of NK cells and T cells, it is not unreasonable to hypothesize that NK cell behavior mirrors 
that of T cells in these settings. A recent publication highlights the role of NK cells in response to STING agonists, showing STING-activating cyclic dinucleotides induce NK cell mediated tumor rejection in several tumor models independent of $\mathrm{CD} 8^{+} \mathrm{T}$ cells (137). Overall, further investigation aiming to uncover additional contributions the STING pathway may add in optimizing immunotherapy treatments and the effects on NK cell therapy are needed. Figure 3C summarizes these potential effects.

\section{MECHANISMS DRIVING NK CELL DYSFUNCTION}

New and emerging studies clearly demonstrate a link between NK cell function and the success of many cancer immunotherapies. NK cells are either direct targets of the immunotherapeutics or are indirectly affected by cells upon which the immunotherapies act on, and positive responses to these immunotherapies are linked to having a functional NK cell population to initiate and prime the immune system for productive anti-tumor response. Thus, understanding mechanisms that can cause dysfunction of NK cells is important for developing and further improving immunotherapeutic strategies for treating cancer (Figure 4). Not only does NK cell dysfunction occur due to immunosuppressive environment progressively established during tumor development, but many of the first-line treatment options also negatively impact NK cell function. The following section will review mechanisms of dysfunction induced by cancer and responses to it.

\section{NK Cells and Cancer-Induced Dysfunction}

NK cells clearly fill a seminal role in orchestrating the body's immunological defenses, thus when the NK cell compartment becomes dysfunctional or damaged, serious health problems can ensue. In an eleven-year prospective cohort study investigating natural immunological host defenses in healthy individuals, participants with low peripheral blood lymphocyte cytotoxic activity had a significantly higher risk for cancer incidence relative to those with medium or high cytotoxic lymphocyte activity (139). In this study, select lifestyle factors such as maintaining a healthy body weight, consuming green vegetables, and not smoking made minor attributions to heightened cytotoxic activity (139). Cytotoxic activity may be used as biomarkers to identify new lifestyle-centered cancer
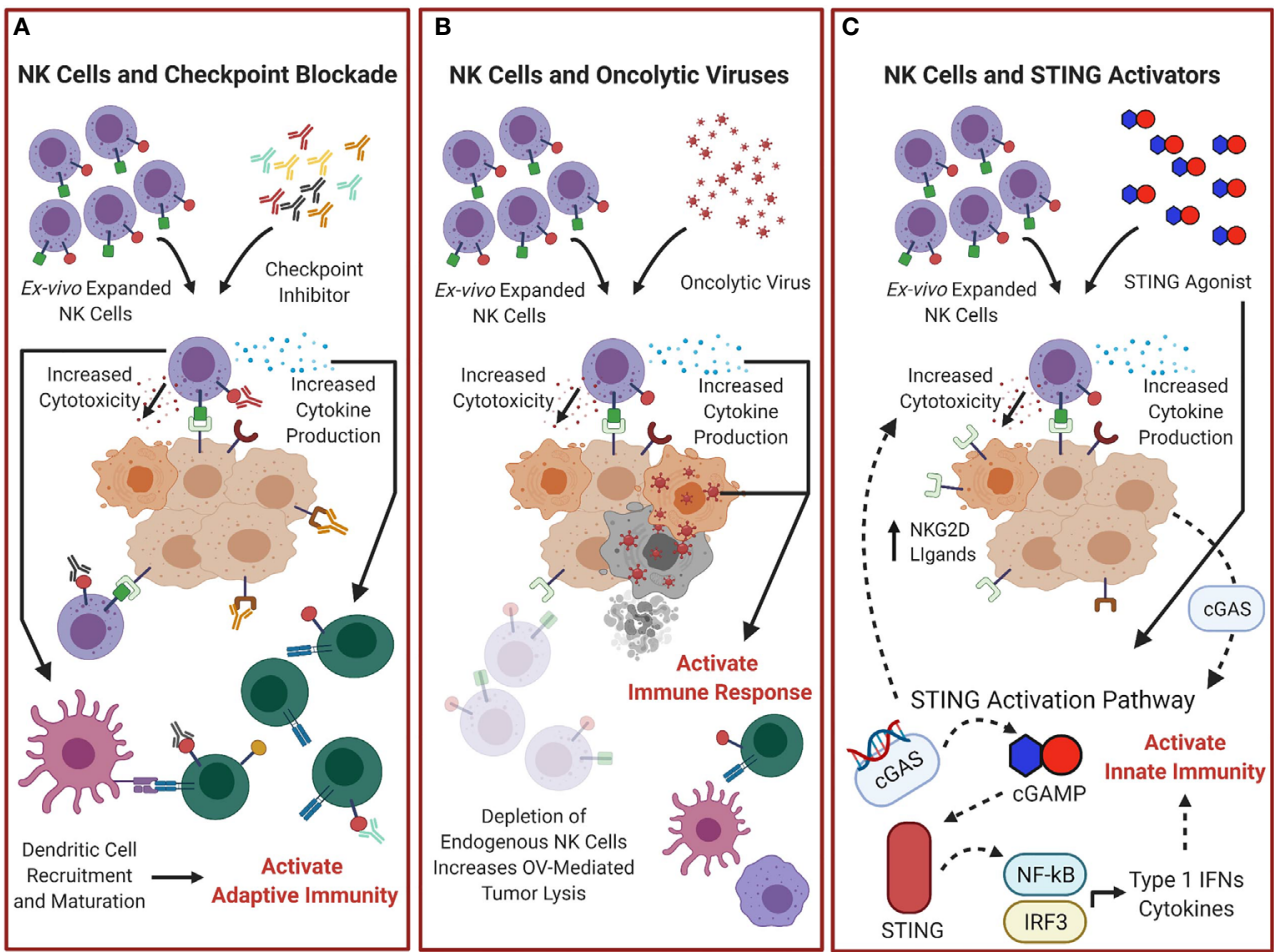

FIGURE 3 | Combination treatments of adoptive NK cells with other Immunotherapies could improve outcomes. (A) Adoptive transfer of NK cells combined with checkpoint inhibitor blockade could increase overall NK cytotoxicity and cytokine production and help control tumor and activate the adaptive immune response. (B) NK cell therapy combined with oncolytic virotherapy (OV) could improve therapeutic efficacy. Depletion of endogenous NK cells would reduce the natural antiviral response and increase OV mediated tumor lysis, and adoptive transfer of NK cells would increase NK cell effector functions and enhance the antitumor response. (C) STING-dependent tumor rejection activated by cGAS expression from tumor cells (107) can be enhanced by combination therapy of STING agonists with NK cells. This would provide enhanced tumor lysis through further activation of the STING pathway, not only activating the innate immunity by stimulating expression of cytokines and Type I IFNs, but by increasing the presence of NK cell activating receptors ligands, which could enhance adoptive NK cell therapy antitumor responses. 
interventions. NK cells are an important brake preventing initial stages of tumor growth, however, as tumors development progresses, NK cell antitumor forces gradually wane as tumor factors promote NK cell exhaustion (31).

Immune evasion is a hallmark of cancer. Tumors employ an arsenal of tactics to escape destruction - either by eluding immunosurveillance or disabling the immune response several of which were previously touched upon in this review. Chronic exposure to inflammatory stimuli is a major factor driving NK cell dysfunction by compromising proliferative capacities and crippling effector functionality, ultimately resulting in pathogenesis. Tumor-associated NK cells exhibit an altered activation receptor repertoire and a diminished cytotoxic capacity compared to NK cells from healthy donors, supporting the assertion that the tumor microenvironment remodels the immune profile (33, 140-142). Tumors secrete cytokines that localize Tregs, myeloid-derived suppressor cells (MDSCs), tumor-associated macrophages, and cancer-associated fibroblasts - major components of the immune-suppressive network - to the tumor milieu $(143,144)$. These cells are a primary source of immunosuppressive cytokines that are responsible for the subdual of the anti-cancer immune response, importantly TGF- $\beta$. TGF- $\beta$ signaling exerts direct effects over the downregulation of several NK cell activation receptors in an array of cancers $(141,145,146)$. Recent studies report that TGF- $\beta$ participates in additional immune-obstructive mechanisms, constructing stromal barriers that exclude lymphocytes from the tumor parenchyma, disrupting NK cell

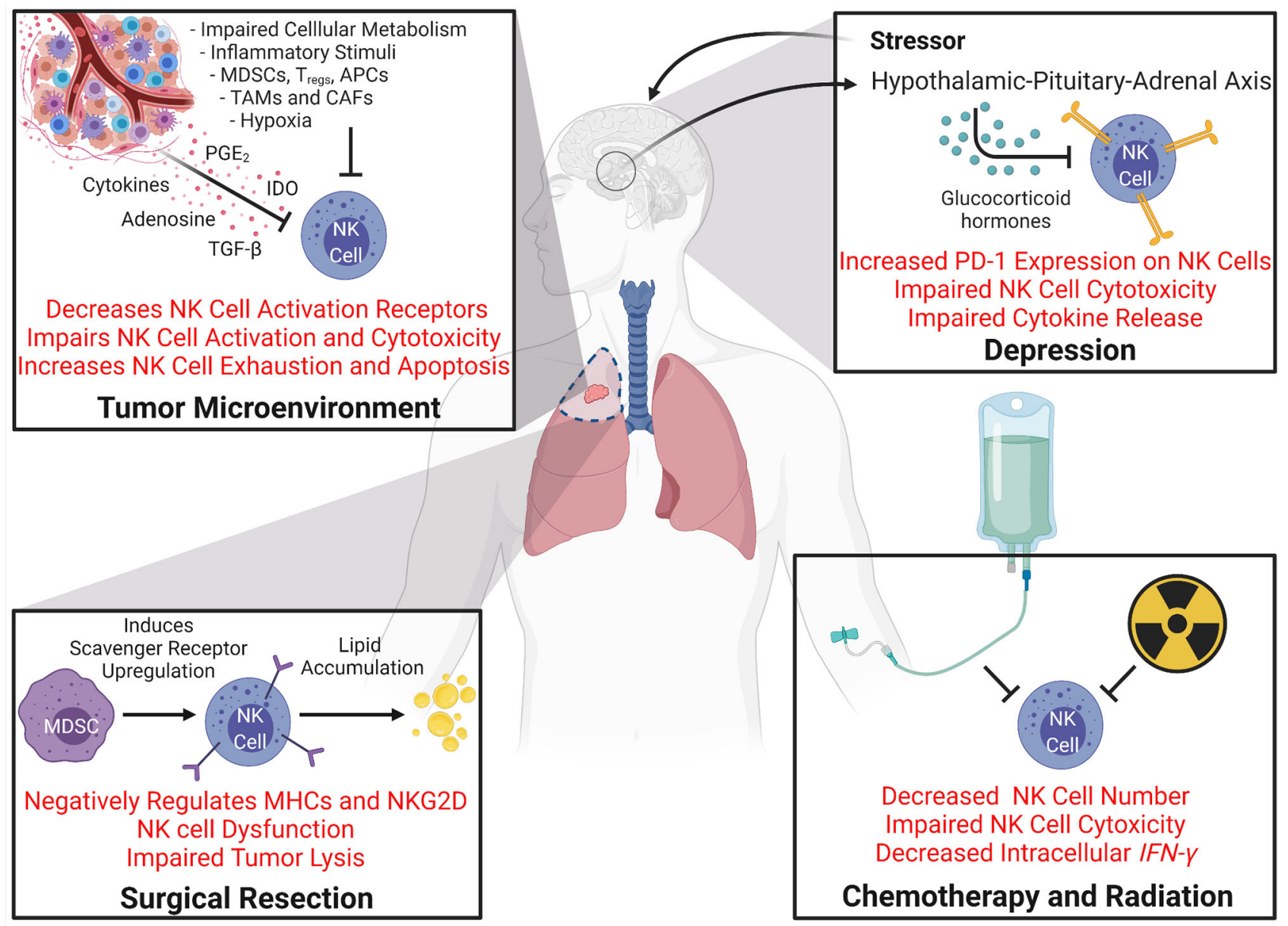

FIGURE 4 | Mechanisms Driving NK Cell Dysfunction During Cancer. Many processes that occur during cancer and cancer therapy can cause dysfunction of NK cells. The tumor microenvironment itself creates a setting full of NK cell inhibitory mechanisms. Impaired cellular metabolism increased inflammatory stimuli, hypoxia, and the localized immunosuppressive cells all can promote NK cell deactivation and impair NK cytotoxicity. Secreted molecules like cytokines, adenosine, TGF- $\beta$, prostaglandin E2 (PGE2) (5), and Indoleamine 2,3-dioxygenase (IDO) in the tumor milieu also promote NK cell downregulation, exhaustion, and apoptosis [reviewed in 138)]. Secondary effects of cancer and cancer therapy, such as depression can also affect NK cell function. Stressors can activate glucocorticoid hormone production via the hypothalamic-pituitary-adrenal axis which can induce PD-1 expression on NK cells and impairs NK cell cytotoxicity and cytokine release. Cancer therapies such as chemotherapy, radiation, and surgical resection can all cause NK cell dysfunction. Both chemotherapy and radiation have been shown to decrease NK cell population and impair NK cell cytotoxicity and IFN- $\gamma$ levels. Surgical resection and perioperative factors have been shown to impair NK cell function. For example, increases in immunosuppressive cell populations such as MDSCs induce scavenger receptor expression on NK cells which promotes lipid accumulation which negatively regulates NK cell receptors and results in NK cell dysfunction. 
tumor-trafficking by negatively modulating the $\mathrm{CX}_{3} \mathrm{CL} 1 /$ $\mathrm{CX}_{3} \mathrm{CR} 1$ chemokine/chemokine receptor axis, curbing $\mathrm{NK}$ cell cytotoxicity in metastatic breast cancer by restricting NK cell metabolism and regulating leukemia cell susceptibility against NK cell targeting by down regulating expression of CD48 (147151). It has also been reported that TGF- $\beta$ signaling within the tumor microenvironment promotes the conversion of $\mathrm{NK}$ cells into intermediate type I innate lymphoid cells that are unable to control local tumor growth and metastasis, driving tumor evasion from the innate immune system (152). Elevated TGF- $\beta$ was also found to upregulate FBP1 in KRAS-mutant lung cancer (31). FBP1-blunted glucose metabolism reduces NK cell viability and disarms the hold NK cells have over tumor initiation (31). Combination anti-PD-L1 and TGF- $\beta$ agonist therapy is now being evaluated (153).

While some methods of immune evasion are more universally applied, cancers exploit a diverse battery of tumor-specific evasion methods as well. Production of soluble IL-2R $\alpha$ (sIL$2 \mathrm{R} / \mathrm{sCD} 25$ ) by Reed-Sternberg (RS) cells in classic Hodgkin lymphoma, binds IL-2, reducing its bioavailability for NK cell activation and proliferation; elevated serum sIL-2R levels are linked to more aggressive disease states and poorer clinical outcomes $(154,155)$. The estrogen pathway is also engaged in the management of the innate and adaptive immune system. Elevated levels of estrogens promote proteinase inhibitor 9 expression, which protects breast cancer cells from granzyme B-induced apoptosis in vitro (156). For a more detailed review of additional tumoral mechanisms shaping NK cell anti-tumor functions, see $(144,157,158)$.

The immunosuppressive tumor microenvironment is also a dominant force in cancer resistance to immunotherapy and checkpoint inhibitors. There is a growing body of evidence that identifies hypoxic stress as a mechanism by which tumors elude immune surveillance. Hypoxia in the tumor microenvironment has broad spectrum debilitating effects that are evident at every level of the anticancer response: impairing $\mathrm{T}$-cell infiltration, blunting the cancer attack mounted by NK cells, attracting immunosuppressive Tregs, and promoting intratumoral heterogeneity $(159,160)$. Hypoxia-driven suppression of NK cell activity has a complex, multimodal mechanism of inhibition. Secretion of TGF- $\beta$ and hypoxia-inducible factor$1 \alpha$ by tumors decreases the NKG2D activating receptor on NK cells and NKG2D ligand on tumor cells, respectively, tipping the scale in favor of NK cell inhibition (161). NK cell proliferation and cytotoxicity are further checked by adenosine A2A receptormediated signaling. The accumulation of extracellular adenosine in the tumor microenvironment by CD39 and CD73 ectonucleotidases is an additional method that protects tumors from the NK cell response (160). The effects of the tumor microenvironment on NK cell dysfunction are summarized in Figure 4 .

\section{NK Cells and Surgery}

Surgical resection of primary tumors and metastatic lymph nodes is often the first-line treatment of cancer. While surgical tumor debulking has immediately apparent benefits, the lingering adverse aftereffects of surgery present a concern for postoperative recovery, residual tumor control, and relapse-free survival. To this effect, a retrospective study on breast cancer, evaluating the mortality distribution for patients undergoing mastectomy versus untreated patients, found a bimodal deathspecific hazard distribution in patients receiving mastectomies (162). In patients with underlying malignancies the immune system is already compromised. The postoperative stress response further weakens NK cell-led immunity, opening an immunological window of opportunity conducive to immune evasion, metastasis development, and accelerated residual tumor outgrowth, which provides a logical explanation for the observed double-peaked pattern (162). A host of perioperative factors surgical trauma, anesthetics, analgesics, and blood transfusions provoke stress-related factors, anti-inflammatory cytokines, and immunosuppressive cell populations that shape the postoperative immune climate. Tai et al. observed an expanded MDSC population in surgically-stressed mice (163). MDSCs induce scavenger receptor upregulation on NK cells which results in lipid accumulation. Postoperative lipid accumulation in NK cells negatively regulates the mouse $\mathrm{MHC}$ receptor repertoire - Ly49A, Ly49E/F, and Ly49G2 - and activating receptor NKG2D, resulting in NK cell dysfunction and impaired tumor lysis (164). Hypercoagulability is an intrinsic response to surgically-induced platelet activation. In this state, fibrin and platelets form peritumoral aggregates around tumor cell emboli, shielding tumor cells from NK cell-mediated extermination and promoting tumor metastasis (165). Surgical support efforts such as anesthetics, analgesics, and allogenic blood transfusion also have direct and indirect effects on immune effector cells, the hypothalamic-pituitary-adrenal (HPA) axis, and sympathetic nervous system. These effects can induce a stress response, contribute to postoperative immune system attenuation, poorer prognoses, and have been identified as risk factors for cancer recurrence (166-170). NK cells isolated from a small cohort of patients receiving transfusions exhibit a decline in NK cell-mediated lysis that is likely shaped by TGF- $\beta$ and soluble HLA-type I and FasL (171). A number of studies report that NK cell impairment can persist for up to thirty days postop (163, 172-174). The mechanisms governing postoperative NK cell dysfunction, summarized in Figure 4 are incompletely understood, however, further insight will aid in honing new clinical interventions.

\section{NK Cells and Chemo/Radiation}

Chemotherapy and radiation are also conventional oncologic interventions. As targeted immunotherapies are gaining traction, there is increasing interest in utilizing these strategies secondary to initial tumor reduction using traditional chemotherapy and radiation techniques. Exploring the largely unstudied immunological consequences chemotherapy and radiation bear on the immune system is important to gauge the potential for success of these treatment pairings. The current body of literature examining the functionality of the immune system after chemotherapy and radiation largely focuses on the immune system as a whole. Following the first round of chemotherapy, the total lymphocyte population showed a significant reduction compared to baseline populations $(175,176)$. The survival 
outcome of these patients was dependent on the capacity for $\mathrm{T}$ cell populations to recover in the wake of chemotherapeuticinduced immunological changes $(175,176)$. In line with the observed effects of chemotherapy on lymphocytes, absolute levels of NK cells and intracellular IFN- $\gamma$ levels were significantly higher prior to radiation or radiation and chemotherapy (177). Supporting this observation, a recent study using an established murine hepatic irradiation model, showed that hepatic irradiation decreased the number of liver resident NK cells and the effect correlated with hepatic irradiation dose (178). Liver resident NK populations did not recover by two months post irradiation and the irradiation prevented differentiation of precursor cells into liver resident NK cells, however adoptive transfer of activated NK cells could alleviate metastatic growth (178).

In patients with hematologic malignancies receiving haploidentical hematopoietic stem cell transplants, cyclophosphamide, a potent immunosuppressive agent, is commonly administered post-transplantation to eliminate alloreactive donor $\mathrm{T}$ lymphocytes and mitigate potential graft$v s$-host disease (179-181). Russo et al. observed decreases in donor-derived NK cell counts following cyclophosphamide infusion, suggesting that highly proliferating graft NK cells are also targets of cyclophosphamide's selective elimination, potentially attenuating the NK cell-mediated graft- $v s$-leukemia attack (182). Two weeks after cyclophosphamide infusion, a second, less mature and less cytotoxic population of donor NK cells begins to emerge, and full reconstitution of a mature NK cell compartment may not be complete for up to a year after transplant $(182,183)$. These studies highlight the need to consider the consequences of chemotherapeutics and radiation treatment on immune cell populations and immunotherapies and potential need for adoptive cell therapies. The effects of chemotherapy and radiation on NK cells is summarized in Figure 4.

\section{NK Cells and Depression}

Depression is a common occurrence in cancer patients and has been highlighted as an important co-morbidity to understand (184). One study showed pooled mean prevalence of depression in cancer patients ranged from $8-24 \%$ (185) and another has shown the odds of being depressed are five times higher in cancer patients (186). Some cancers can release chemicals that are thought to cause depression and even certain cancer treatments, such as chemotherapy and corticosteroids, are associated with depression (187). Glucocorticoids are steroid hormones released following activation of the HPA axis and are key regulators of the innate and adaptive immune responses, including NK cell activity (188), forging a link between the neuroendocrine and immune systems (Figure 4). Interestingly, hyperactivity of the HPA axis is observed in patients with depression, resulting in excessive glucocorticoid release, impairment of NK cell cytotoxicity, and subsequent cancer progression (62). Glucocorticoids bind the ubiquitously expressed glucocorticoid receptor (GR), curbing immunemediated inflammation via suppression of the cytolytic activity of and the production of pro-inflammatory cytokines by immune cells. A study by Yang et al. examining glucocorticoid release in response to psychological distress found that stress-induced glucocorticoids led to upregulation of the immunosuppressive factor $T s c 22 d 3$, resulting in repression of the dendritic cellmediated type I IFN response required for the activation of adaptive anticancer surveillance efforts (189). Endogenous glucocorticoids are also associated with increased de novo PD1 expression on NK cells. Glucocorticoids in combination with IL-15 and IL-18 selectively induce PD-1 expression on splenic NK cells, which negatively regulates the IFN- $\gamma$ response of NK cells (187). These results establish the GR-PD-1 axis as a novel mechanism of neuroimmune regulation.

Glucocorticoids are often prescribed to palliate some of the side effects of chemotherapies and radiation, however, the data presented above suggests exogenous glucocorticoids may actually obstruct therapy-driven immune stimulation and control of tumor growth. Further research is required to modify current standard patient management strategies. In light of favorable data, pharmacologic and psychosocial therapies targeted to decrease glucocorticoid pathway activity may be considered as supplemental therapies to harness the full potential of immunotherapies and checkpoint inhibitors.

\section{CURRENT ADVANCES IN NK CELL THERAPIES}

A functional NK cell population is imperative to improving the efficacy and durability of cancer immunotherapies and combination treatments with adoptive NK cell therapies is an emerging strategy. NK cells comprise a minor portion of the circulating lymphocyte population. Devising protocols to selectively expand sufficiently large numbers of NK cells ex vivo for clinical infusion therapies has precluded NK cell-based therapies until recently, the recent advances are summarized in Figure 5. Co-culturing NK cells with K562 feeder cells engineered to express membrane bound 4-1BBL and IL-15 or IL-21 has proven to be an effective method for attaining robust NK cell expansion $(190,191)$. Preliminary data from a Phase I clinical trial evaluating the feasibility, safety, and dose-escalation response of high-dose infusion of haploidentical NK cells, expanded ex vivo using membrane bound IL-21 (mbIL21)K562 feeder cells, in high-risk leukemia patients has generated encouraging data, with low observed rates of relapse, viral reactivation, graft- $v s$-host disease, and no dose-related toxicity (35). Updates from the Phase II extension of the study have continued to be positive, with one year relapse at $8 \%$ and two year progression-free survival at $66 \%$ in the 25 patients enrolled to date (192). Two additional Phase I studies are currently underway for patients with relapsed/refractory myeloid leukemias. With 13 patients treated thus far, 69\% have achieved complete remission (193).

Despite taking precautions, concerns over the risk feeder cellexpanded NK cells carry for the potential infusion of tumorderived feeder cells or tumorous material to patients have led to the exploration of feeder cell-free NK expansion methods. 


\section{Sources of NK cells}

\section{Peripheral Blood Stem Cells NK cell lines}

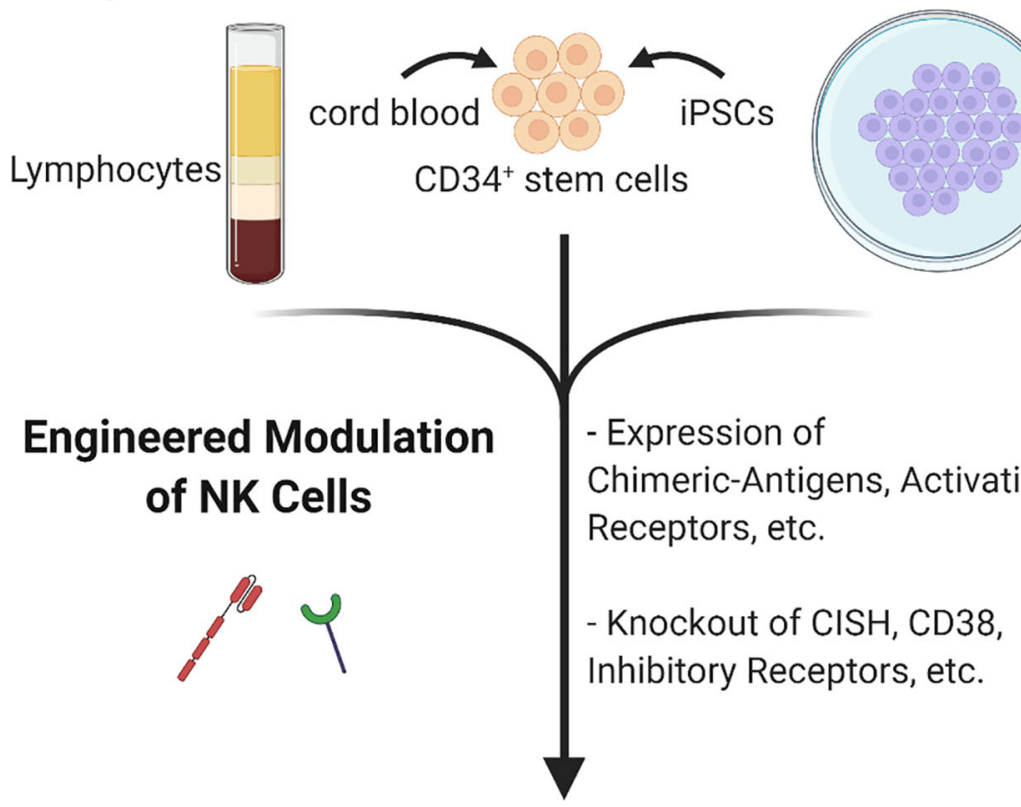

\section{Ex-Vivo Activation/Cultivation of NK cells}

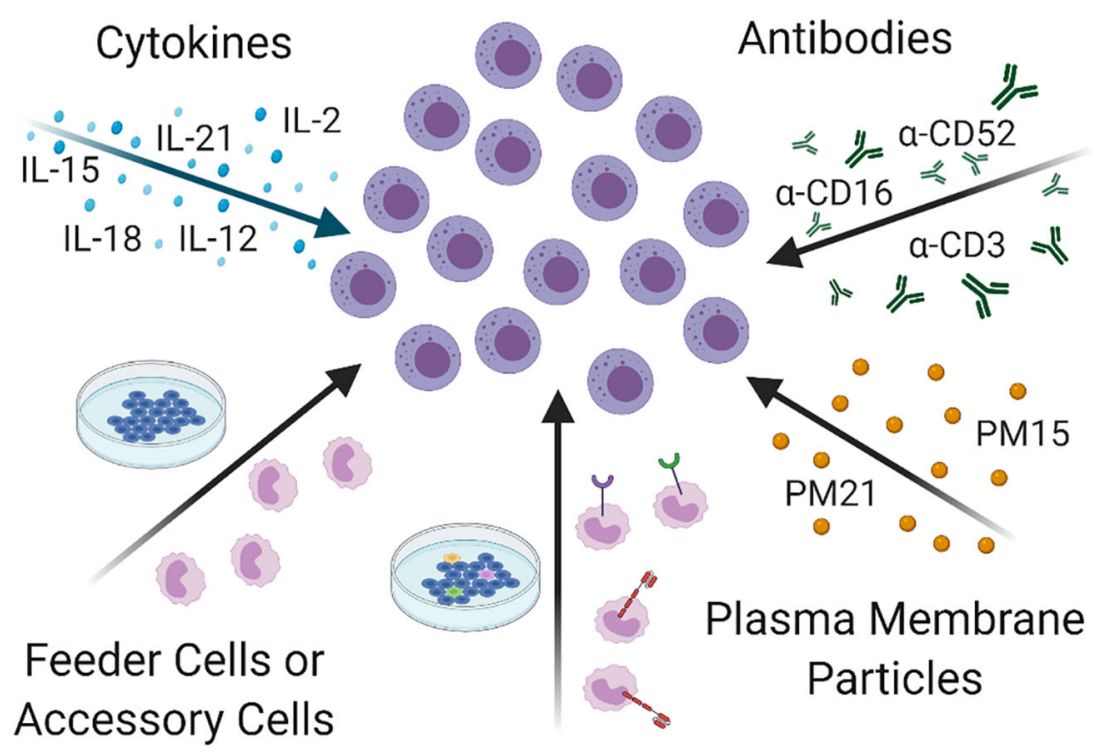

\section{Modified Feeder Cells or Accessory Cells}

FIGURE 5 | Sources and Cultivation of NK cells. NK cells can be extracted from peripheral blood or be differentiated from CD34+ $4^{+}$stem cells sourced from cord blood, placenta or manufactured from iPSCs. Tumor-derived NK cell lines are also being developed to expand large numbers of NK cells ex vivo. NK cells can be engineered to express cytokines, natural or modified receptors, or transformed to knock out inhibitory receptors and other molecules to enhance their cultivation, targeting and activity under TME. Unmodified or genetically engineered NK cells can be further activated and/or expanded by culturing in the presence of cytokines or antibodies alone or in combination with co-culturing with feeder cells or accessory cells, which themselves can be modified for greater activation. Feeder cell-free NK expansion methods have also been developed such as using plasma membrane particles that provide robust expansion of highly cytotoxic NK cells comparable to feeder cell- based methods without the drawbacks and safety concerns. 
Oyer et al., pioneered a novel, feeder cell-free NK cell expansion method using plasma membrane particles (PM-particles) derived from K562 feeder cells genetically engineered to express $4-1 \mathrm{BBL}$ and mbIL21 or mbIL15 $(194,195)$. Ex vivo NK cell expansion and cytotoxicity levels using particles were comparable to levels achieved using feeder cell methods (195). Haploidentical PM21 - NK cells are currently tested in Phase II clinical trials (NCT 04395092) as post-transplant relapse prevention in AML and myelodysplastic syndromes.

An alternative approach that avoids the use of feeder cells utilizes short preactivation with cytokines. The combined IL-12, IL-15, and IL-18 in vitro preactivation of NK cells does not lead to expansion of $\mathrm{NK}$ cell in vitro but is capable of provoking a durable memory-like IFN- $\gamma$ response upon secondary stimulation (196). These memory-like NK cells, referred to as cytokine induced memory-like (CIML) NK cells, demonstrated heightened antileukemia responses that persisted for one month after infusion into patients, propelling four out of nine patients into complete remission $(197,198)$. There are currently seven ongoing clinical trials listed in the NCT database using CIML NK cells in combination treatments for AML and multiple myeloma. NK cell cytokine pre-activation may be incorporated into current ex vivo therapeutic NK cell manufacturing practices, allowing for NK cell memory to be harnessed and exploited to further amplify other immunotherapies.

The above mentioned methods utilize PBMCs as source of NK cells but other sources such as cord blood, placental or iPSCs derived stem cells have also been utilized as starting source for NK cells $(199,200)$ [reviewed in (201)]. Current trends in NK cell therapy are also focused on using genetic and non-genetic methods to improve NK cell expansion, cytotoxicity, targeting, homing, and to increase lifespan $(189,202)$ [reviewed in (203, 204)]. Among them, chimeric antigen receptor (CAR)engineered NK cells have been a major emerging method for cancer therapy. For example, an ErbB2 (HER2)-specific CARNK is currently being used in a phase I clinical trial for treatment of glioblastoma patients (205). In a phase I and II clinical trial HLA-mismatched anti-CD19 CAR-NK cells derived from cord blood was administered to patients with B-Lymphoid malignancies and saw a $73 \%$ response (206) and now early phase I clinical trials are further investigating CD19 and CD22 CAR-NK cells in Refractory B-cell Lymphoma patients, NCT03690310 and NCT03692767. Recently an open label pilot study also began to evaluate the safety and feasibility of CAR-NK cells targeting NKG2D ligands in the treatment of metastatic solid tumors, NCT03415100. Many recent reviews on the subject have been published, see (207-211). For a more detailed review of the current state of NK cell ex vivo cultivation see (207) and the use of adoptive NK cell immunotherapies, see (212).

\section{CONCLUSION}

The immune system's carefully orchestrated anti-tumor response draws its power from the concerted contributions of the innate and adaptive immune arms. The NK cell kicks off the first leg of the immunological response: patients lacking a robust NK cell compartment are unable to mount strong killing of malignant cells and fail to harness the full therapeutic effects of immunotherapies.

This presents a strong argument in favor of employing adoptive NK cell transfer prior to or concomitantly with immunotherapies to jumpstart the immune response. Precursory adoptive NK cell transfer may reconstitute the NK cell compartment, providing the necessary priming of the immune system for optimal activity of subsequent effector populations and maximizing therapeutic efficacy.

Immunotherapy is a promising new frontier in cancer treatment. Great strides are being made in the breadth and availability of cancer therapeutics, however, variability in patient responses remains a chronic barrier to further success. Cytotoxic T lymphocytes are a major focus of immunotherapies, however, increasing reports suggest other effector populations are critical to a positive therapeutic response and should be given equal attention in study design. Dually tasked with effector and regulatory functions, the NK cell is the linchpin of the complex immune response: directly responsible for lysis of tumor cells through ADCC and the clearance of MHC-compromised cells in the primary immune response and priming of the tumor microenvironment through PD-L1 induction on tumors and recruitment of DCs and subsequently $\mathrm{T}$ cells for the secondary adaptive immune response. Future immunotherapy treatment protocols should consider deeply the synergy of the innate and adaptive immune system in order to further improve cancer treatment and long-term tumor control.

\section{AUTHOR CONTRIBUTIONS}

KS: Conceptualization, literature research, writing - review \& editing. TC-P: Literature research, writing - figure preparation, review \& editing. AC: Conceptualization, literature research, funding acquisition, project administration, resources, supervision, writing - review \& editing. All authors contributed to the article and approved the submitted version.

\section{FUNDING}

We would like to thank the Florida Department of Health, James and Ester King Biomedical Research Grant program (grant\# 9JK04 to AJC) and The Guillot-Henley Family AML Research Fund in loving memory of William L. Guillot for financial support.

\section{ACKNOWLEDGMENTS}

All figures were created with BioRender.com. Retrieved from https://app.biorender.com/biorender-templates. 


\section{REFERENCES}

1. Iwai Y, Hamanishi J, Chamoto K, Honjo T. Cancer Immunotherapies Targeting the PD-1 Signaling Pathway. J BioMed Sci (2017) 24(1):26. doi: 10.1186/s12929-017-0329-9

2. Ghahremanloo A, Soltani A, Modaresi SMS, Hashemy SI. Recent Advances in the Clinical Development of Immune Checkpoint Blockade Therapy. Cell Oncol (Dordr) (2019) 42(5):609-26. doi: 10.1007/s13402-019-00456-w

3. Chen L, Han X. Anti-PD-1/PD-L1 Therapy of Human Cancer: Past, Present, and Future. J Clin Invest (2015) 125(9):3384-91. doi: 10.1172/jci80011

4. Binnewies M, Roberts EW, Kersten K, Chan V, Fearon DF, Merad M, et al. Understanding the Tumor Immune Microenvironment (TIME) for Effective Therapy. Nat Med (2018) 24(5):541-50. doi: 10.1038/s41591018-0014-x

5. Böttcher JP, Bonavita E, Chakravarty P, Blees H, Cabeza-Cabrerizo M, Sammicheli S, et al. Nk Cells Stimulate Recruitment of cDC1 Into the Tumor Microenvironment Promoting Cancer Immune Control. Cell (2018) 172 (5):1022-37.e14. doi: 10.1016/j.cell.2018.01.004

6. Barry KC, Hsu J, Broz ML, Cueto FJ, Binnewies M, Combes AJ, et al. A Natural Killer-Dendritic Cell Axis Defines Checkpoint Therapy-Responsive Tumor Microenvironments. Nat Med (2018) 24(8):1178-91. doi: 10.1038/ s41591-018-0085-8

7. Roda JM, Parihar R, Magro C, Nuovo GJ, Tridandapani S, Carson WE,3. Natural Killer Cells Produce T Cell-Recruiting Chemokines in Response to Antibody-Coated Tumor Cells. Cancer Res (2006) 66(1):517-26. doi: 10.1158/0008-5472.Can-05-2429

8. Guillerey C, Huntington ND, Smyth MJ. Targeting Natural Killer Cells in Cancer Immunotherapy. Nat Immunol (2016) 17(9):1025-36. doi: 10.1038/ ni. 3518

9. Screpanti V, Wallin RP, Grandien A, Ljunggren HG. Impact of FASLinduced Apoptosis in the Elimination of Tumor Cells by NK Cells. Mol Immunol (2005) 42(4):495-9. doi: 10.1016/j.molimm.2004.07.033

10. Simon AK, Gallimore A, Jones E, Sawitzki B, Cerundolo V, Screaton GR. Fas Ligand Breaks Tolerance to Self-Antigens and Induces Tumor Immunity Mediated by Antibodies. Cancer Cell (2002) 2(4):315-22. doi: 10.1016/ S1535-6108(02)00151-4

11. Zamai L, Ahmad M, Bennett IM, Azzoni L, Alnemri ES, Perussia B. Natural Killer (Nk) Cell-mediated Cytotoxicity: Differential Use of TRAIL and Fas Ligand by Immature and Mature Primary Human Nk Cells. J Exp Med (1998) 188(12):2375-80. doi: 10.1084/jem.188.12.2375

12. Wigginton JM, Gruys E, Geiselhart L, Subleski J, Komschlies KL, Park J-W, et al. Ifn- $\gamma$ and Fas/FasL are Required for the Antitumor and Antiangiogenic Effects of IL-12/pulse IL-2 Therapy. J Clin Invest (2001) 108(1):51-62. doi: $10.1172 /$ JCI10128

13. Jong AY, Wu CH, Li J, Sun J, Fabbri M, Wayne AS, et al. Large-Scale Isolation and Cytotoxicity of Extracellular Vesicles Derived From Activated Human Natural Killer Cells. J Extracell Vesicles (2017) 6(1):1294368. doi: 10.1080/20013078.2017.1294368

14. Fabbri M. Natural Killer Cell-Derived Vesicular Mirnas: A New Anticancer Approach? Cancer Res (2020) 80(1):17-22. doi: 10.1158/ 0008-5472.Can-19-1450

15. Di Pace AL, Tumino N, Besi F, Alicata C, Conti LA, Munari E, et al. Characterization of Human Nk Cell-Derived Exosomes: Role of DNAM1 Receptor in Exosome-Mediated Cytotoxicity Against Tumor. Cancers (2020) 12(3):661. doi: 10.3390/cancers12030661

16. Choi JW, Lim S, Kang JH, Hwang SH, Hwang KC, Kim SW, et al. Proteome Analysis of Human Natural Killer Cell Derived Extracellular Vesicles for Identification of Anticancer Effectors. Molecules (2020) 25(21):5216. doi: $10.3390 /$ molecules 25215216

17. Lugini L, Cecchetti S, Huber V, Luciani F, Macchia G, Spadaro F, et al. Immune Surveillance Properties of Human Nk Cell-Derived Exosomes. J Immunol (2012) 189(6):2833-42. doi: 10.4049/jimmunol.1101988

18. Kos FJ, Engleman EG. Requirement for Natural Killer Cells in the Induction of Cytotoxic T Cells. J Immunol (1995) 155(2):578-84.

19. Kurosawa S, Harada M, Matsuzaki G, Shinomiya Y, Terao H, Kobayashi N, et al. Early-Appearing Tumour-Infiltrating Natural Killer Cells Play a Crucial Role in the Generation of Anti-Tumour T Lymphocytes. Immunology (1995) 85(2):338-46.
20. Manetti R, Parronchi P, Giudizi MG, Piccinni MP, Maggi E, Trinchieri G et al. Natural Killer Cell Stimulatory Factor (Interleukin 12 [IL-12]) Induces T Helper Type 1 (Th1)-specific Immune Responses and Inhibits the Development of IL-4-producing Th Cells. J Exp Med (1993) 177(4):1199204. doi: 10.1084/jem.177.4.1199

21. Goding SR, Yu S, Bailey LM, Lotze MT, Basse PH. Adoptive Transfer of Natural Killer Cells Promotes the Anti-Tumor Efficacy of T Cells. Clin Immunol (2017) 177:76-86. doi: 10.1016/j.clim.2016.06.013

22. Morandi B, Mortara L, Chiossone L, Accolla RS, Mingari MC, Moretta L, et al. Dendritic Cell Editing by Activated Natural Killer Cells Results in a More Protective Cancer-Specific Immune Response. PloS One (2012) 7(6): e39170-e. doi: 10.1371/journal.pone.0039170

23. Cichocki F, Bjordahl R, Gaidarova S, Mahmood S, Abujarour R, Wang H, et al. Ipsc-Derived NK Cells Maintain High Cytotoxicity and Enhance In Vivo Tumor Control in Concert With T Cells and anti-PD-1 Therapy. Sci Transl Med (2020) 12(568):eaaz5618. doi: 10.1126/scitranslmed.aaz5618

24. Kalinski P, Mailliard RB, Giermasz A, Zeh HJ, Basse P, Bartlett DL, et al. Natural Killer-Dendritic Cell Cross-Talk in Cancer Immunotherapy. Expert Opin Biol Ther (2005) 5(10):1303-15. doi: 10.1517/14712598.5.10.1303

25. Dong W, Wu X, Ma S, Wang Y, Nalin AP, Zhu Z, et al. The Mechanism of anti-PD-L1 Antibody Efficacy Against PD-L1 Negative Tumors Identifies NK Cells Expressing PD-L1 as a Cytolytic Effector. Cancer Discov (2019) 9 (10):1422-37. doi: 10.1158/2159-8290.cd-18-1259

26. Hsu J, Hodgins JJ, Marathe M, Nicolai CJ, Bourgeois-Daigneault MC, Trevino TN, et al. Contribution of NK Cells to Immunotherapy Mediated by PD-1/PD-L1 Blockade. J Clin Invest (2018) 128(10):4654-68. doi: $10.1172 /$ JCI99317

27. Lee H, Quek C, Silva I, Tasker A, Batten M, Rizos H, et al. Integrated Molecular and Immunophenotypic Analysis of NK Cells in anti-PD-1 Treated Metastatic Melanoma Patients. Oncoimmunology (2019) 8(2): e1537581. doi: 10.1080/2162402X.2018.1537581

28. Pallmer K, Oxenius A. Recognition and Regulation of T Cells by NK Cells. Front Immunol (2016) 7:251. doi: 10.3389/fimmu.2016.00251

29. Balch CM, Tilden AB, Dougherty PA, Cloud GA. Depressed Levels of Granular Lymphocytes With Natural Killer (NK) Cell Function in 247 Cancer Patients. Ann Surg (1983) 198(2):192-9. doi: 10.1097/00000658198308000-00014

30. Angka L, Khan ST, Kilgour MK, Xu R, Kennedy MA, Auer RC. Dysfunctional Natural Killer Cells in the Aftermath of Cancer Surgery. Int J Mol Sci (2017) 18(8):1787. doi: 10.3390/ijms18081787

31. Cong J, Wang X, Zheng X, Wang D, Fu B, Sun R, et al. Dysfunction of Natural Killer Cells by FBP1-Induced Inhibition of Glycolysis During Lung Cancer Progression. Cell Metab (2018) 28(2):243-55.e5. doi: 10.1016/ j.cmet.2018.06.021

32. Shen MJ, Xu LJ, Yang L, Tsai Y, Keng PC, Chen Y, et al. Radiation Alters PDL1/NKG2D Ligand Levels in Lung Cancer Cells and Leads to Immune Escape From NK Cell Cytotoxicity Via IL-6-MEK/Erk Signaling Pathway. Oncotarget (2017) 8(46):80506-20. doi: 10.18632/oncotarget.19193

33. Mantovani S, Oliviero B, Lombardi A, Varchetta S, Mele D, Sangiovanni A, et al. Deficient Natural Killer Cell Nkp30-Mediated Function and Altered Ncr3 Splice Variants in Hepatocellular Carcinoma. Hepatol (Baltimore Md) (2019) 69(3):1165-79. doi: 10.1002/hep.30235

34. Zheng Y, Li Y, Lian J, Yang H, Li F, Zhao S, et al. Tnf- $\alpha$-Induced Tim-3 Expression Marks the Dysfunction of Infiltrating Natural Killer Cells in Human Esophageal Cancer. J Trans Med (2019) 17(1):165. doi: 10.1186/ s12967-019-1917-0

35. Ciurea SO, Schafer JR, Bassett R, Denman CJ, Cao K, Willis D, et al. Phase 1 Clinical Trial Using mbIL21 Ex Vivo-Expanded Donor-Derived NK Cells After Haploidentical Transplantation. Blood (2017) 130(16):1857-68. doi: 10.1182/blood-2017-05-785659

36. Baggio L, Laureano ÁM, Silla L, Lee DA. Natural Killer Cell Adoptive Immunotherapy: Coming of Age. Clin Immunol (2017) 177:3-11. doi: 10.1016/j.clim.2016.02.003

37. Zahavi D, Weiner L. Monoclonal Antibodies in Cancer Therapy. Antibodies (Basel) (2020) 9(3):34. doi: 10.3390/antib9030034

38. Robert C, Schachter J, Long GV, Arance A, Grob JJ, Mortier L, et al Pembrolizumab Versus Ipilimumab in Advanced Melanoma. New Engl J Med (2015) 372(26):2521-32. doi: 10.1056/NEJMoa1503093 
39. Keytruda (pembrolizumab). Package Insert. Merck Sharp \& Dohme Corporation (2019).

40. Kwok G, Yau TC, Chiu JW, Tse E, Kwong YL. Pembrolizumab (Keytruda). Hum Vaccin Immunother (2016) 12(11):2777-89. doi: 10.1080/21645515. 2016.1199310

41. Doi T, Piha-Paul SA, Jalal SI, Mai-Dang H, Yuan S, Koshiji M, et al. Pembrolizumab (MK-3475) for Patients (Pts) With Advanced Esophageal Carcinoma: Preliminary Results From KEYNOTE-028. J Clin Oncol (2015) 33(15_suppl):4010-. doi: 10.1200/jco.2015.33.15_suppl.4010

42. Ott PA, Fernandez MEE, Hiret S, Kim D-W, Moss RA, Winser T, et al. Pembrolizumab (MK-3475) in Patients (Pts) With Extensive-Stage Small Cell Lung Cancer (SCLC): Preliminary Safety and Efficacy Results From KEYNOTE-028. J Clin Oncol (2015) 33(15_suppl):7502-. doi: 10.1200/ jco.2015.33.15_suppl.7502

43. O'neil B, Wallmark J, Lorente D, Elez E, Raimbourg J, Gomez-Roca C, et al. Pembrolizumab (MK-3475) for Patients (Pts) With Advanced Colorectal Carcinoma (CRC): Preliminary Results From KEYNOTE-028. Eur J Cancer (2015) 51(433):30304-5. doi: 10.1016/S0959-8049(16)30304-5

44. Plimack ER, Bellmunt J, Gupta S, Berger R, Chow LQ, Juco J, et al. Safety and Activity of Pembrolizumab in Patients With Locally Advanced or Metastatic Urothelial Cancer (KEYNOTE-012): A non-Randomised, Open-Label, Phase 1b Study. Lancet Oncol (2017) 18(2):212-20. doi: 10.1016/s14702045(17)30007-4

45. Muro K, Chung HC, Shankaran V, Geva R, Catenacci D, Gupta S, et al. Pembrolizumab for Patients With PD-L1-positive Advanced Gastric Cancer (KEYNOTE-012): A Multicentre, Open-Label, Phase 1b Trial. Lancet Oncol (2016) 17(6):717-26. doi: 10.1016/s1470-2045(16)00175-3

46. Chow LQM, Haddad R, Gupta S, Mahipal A, Mehra R, Tahara M, et al. Antitumor Activity of Pembrolizumab in Biomarker-Unselected Patients With Recurrent and/or Metastatic Head and Neck Squamous Cell Carcinoma: Results From the Phase Ib KEYNOTE-012 Expansion Cohort. J Clin Oncol (2016) 34(32):3838-45. doi: 10.1200/jco.2016.68.1478

47. Nanda R, Chow LQ, Dees EC, Berger R, Gupta S, Geva R, et al. Pembrolizumab in Patients With Advanced Triple-Negative Breast Cancer: Phase Ib KEYNOTE-012 Study. J Clin Oncol (2016) 34(21):24607. doi: $10.1200 / j$ co.2015.64.8931

48. Schmidt EV. Developing Combination Strategies Using PD-1 Checkpoint Inhibitors to Treat Cancer. Semin Immunopathol (2019) 41(1):21-30. doi: 10.1007/s00281-018-0714-9

49. Bendell JC BP, Bang YJ, LoRusso P, Hodi S, Gordon M, et al. Abstract CT302: Phase Ia/Ib Dose-Escalation Study of the Anti-TIGIT Antibody Tiragolumab as a Single Agent and in Combination With Atezolizumab in Patients With Advanced Solid Tumors. Cancer Res (2020) 80(16 Supplement):CT302. doi: 10.1158/1538-7445.AM2020-CT302

50. Aptsiauri N, Cabrera T, Garcia-Lora A, Lopez-Nevot MA, Ruiz-Cabello F, Garrido F. MHC class I antigens and immune surveillance in transformed cells. Int Rev Cytol (2007) 256:139-89. doi: 10.1016/S0074-7696(07) 56005-5

51. Rodig SJ, Gusenleitner D, Jackson DG, Gjini E, Giobbie-Hurder A, Jin C, et al. MHC Proteins Confer Differential Sensitivity to CTLA-4 and PD-1 Blockade in Untreated Metastatic Melanoma. Sci Trans Med (2018) 10(450): eaar3342. doi: 10.1126/scitranslmed.aar3342

52. Johnson DB, Estrada MV, Salgado R, Sanchez V, Doxie DB, Opalenik SR, et al. Melanoma-Specific MHC-II Expression Represents a TumourAutonomous Phenotype and Predicts Response to anti-PD-1/PD-L1 Therapy. Nat Commun (2016) 7:10582-. doi: 10.1038/ncomms10582

53. Moynihan KD, Opel CF, Szeto GL, Tzeng A, Zhu EF, Engreitz JM, et al. Eradication of Large Established Tumors in Mice by Combination Immunotherapy That Engages Innate and Adaptive Immune Responses. Nat Med (2016) 22(12):1402-10. doi: 10.1038/nm.4200

54. Scheuerpflug A, Ahmetlić F, Bauer V, Riedel T, Röcken M, Mocikat R. The Role of Dendritic Cells for Therapy of B-cell Lymphoma With Immune Checkpoint Inhibitors. Cancer Immunol Immunother (2020) 70(5):1343-50. doi: 10.1007/s00262-020-02767-6

55. Ceci C, Atzori MG, Lacal PM, Graziani G. Targeting Tumor-Associated Macrophages to Increase the Efficacy of Immune Checkpoint Inhibitors: A Glimpse Into Novel Therapeutic Approaches for Metastatic Melanoma. Cancers (2020) 12(11):3401. doi: 10.3390/cancers12113401
56. Pesce S, Trabanelli S, Di Vito C, Greppi M, Obino V, Guolo F, et al. Cancer Immunotherapy by Blocking Immune Checkpoints on Innate Lymphocytes. Cancers (2020) 12(12):3504. doi: 10.3390/cancers12123504

57. Tseng HC, Bui V, Man YG, Cacalano N, Jewett A. Induction of Split Anergy Conditions Natural Killer Cells to Promote Differentiation of Stem Cells Through Cell-Cell Contact and Secreted Factors. Front Immunol (2014) 5:269. doi: 10.3389/fimmu.2014.00269

58. Kaur K, Topchyan P, Kozlowska AK, Ohanian N, Chiang J, Maung PO, et al. Super-Charged NK Cells Inhibit Growth and Progression of Stem-Like/ Poorly Differentiated Oral Tumors In Vivo in Humanized BLT Mice; Effect on Tumor Differentiation and Response to Chemotherapeutic Drugs. Oncoimmunology (2018) 7(5):e1426518. doi: 10.1080/2162402X. 2018.1426518

59. Ruscetti M, Leibold J, Bott MJ, Fennell M, Kulick A, Salgado NR, et al. NK Cell-Mediated Cytotoxicity Contributes to Tumor Control by a Cytostatic Drug Combination. Science (2018) 362(6421):1416-22. doi: 10.1126/ science.aas 9090

60. Benson DM, Jr., Bakan CE, Mishra A, Hofmeister CC, Efebera Y, Becknell B, et al. The PD-1/PD-L1 Axis Modulates the Natural Killer Cell Versus Multiple Myeloma Effect: A Therapeutic Target for CT-011, a Novel Monoclonal anti-PD-1 Antibody. Blood (2010) 116(13):2286-94. doi: 10.1182/blood-2010-02-271874

61. Concha-Benavente F, Kansy B, Moskovitz J, Moy J, Chandran U, Ferris RL. Pd-L1 Mediates Dysfunction in Activated Pd-1(+) NK Cells in Head and Neck Cancer Patients. Cancer Immunol Res (2018) 6(12):1548-60. doi: 10.1158/2326-6066.CIR-18-0062

62. Zhao Y, Jia Y, Shi T, Wang W, Shao D, Zheng X, et al. Depression Promotes Hepatocellular Carcinoma Progression Through a Glucocorticoids Mediated Up-Regulation of PD-1 Expression in Tumor Infiltrating NK Cells. Carcinogenesis (2019) 40(9):1132-41. doi: 10.1093/carcin/bgz017

63. Oyer JL, Gitto SB, Altomare DA, Copik AJ. Pd-L1 Blockade Enhances AntiTumor Efficacy of NK Cells. Oncoimmunology (2018) 7(11):e1509819-e. doi: 10.1080/2162402X.2018.1509819

64. Gibney GT, Weiner LM, Atkins MB. Predictive Biomarkers for Checkpoint Inhibitor-Based Immunotherapy. Lancet Oncol (2016) 17(12):e542-e51. doi: 10.1016/s1470-2045(16)30406-5

65. Ancevski Hunter K, Socinski MA, Villaruz LC. Pd-L1 Testing in Guiding Patient Selection for PD-1/PD-L1 Inhibitor Therapy in Lung Cancer. Mol Diagn Ther (2018) 22(1):1-10. doi: 10.1007/s40291-017-0308-6

66. Chen XJ, Yuan SQ, Duan JL, Chen YM, Chen S, Wang Y, et al. The Value of PD-L1 Expression in Predicting the Efficacy of Anti-PD-1 or Anti-PD-L1 Therapy in Patients With Cancer: A Systematic Review and Meta-Analysis. Dis Markers (2020) 2020:6717912. doi: 10.1155/2020/6717912

67. Barlesi F, Vansteenkiste J, Spigel D, Ishii H, Garassino M, de Marinis F, et al. Avelumab Versus Docetaxel in Patients With Platinum-Treated Advanced non-Small-Cell Lung Cancer (JAVELIN Lung 200): An Open-Label, Randomised, Phase 3 Study. Lancet Oncol (2018) 19(11):1468-79. doi: 10.1016/S1470-2045(18)30673-9

68. Herbst RS, Soria JC, Kowanetz M, Fine GD, Hamid O, Gordon MS, et al. Predictive Correlates of Response to the anti-PD-L1 Antibody MPDL3280A in Cancer Patients. Nature (2014) 515(7528):563-7. doi: 10.1038/ nature14011

69. Powles T, Eder JP, Fine GD, Braiteh FS, Loriot Y, Cruz C, et al. Mpdl3280a (anti-PD-L1) Treatment Leads to Clinical Activity in Metastatic Bladder Cancer. Nature (2014) 515(7528):558-62. doi: 10.1038/nature13904

70. Ballbach M, Dannert A, Singh A, Siegmund DM, Handgretinger R, Piali L, et al. Expression of Checkpoint Molecules on Myeloid-Derived Suppressor Cells. Immunol Lett (2017) 192:1-6. doi: 10.1016/j.imlet.2017.10.001

71. Peng Q, Qiu X, Zhang Z, Zhang S, Zhang Y, Liang Y, et al. Pd-L1 on Dendritic Cells Attenuates T Cell Activation and Regulates Response to Immune Checkpoint Blockade. Nat Commun (2020) 11(1):4835. doi: 10.1038/s41467-020-18570-x

72. Judge SJ, Dunai C, Aguilar EG, Vick SC, Sturgill IR, Khuat LT, et al. Minimal PD-1 Expression in Mouse and Human NK Cells Under Diverse Conditions. J Clin Invest (2020) 130(6):3051-68. doi: 10.1172/jci133353

73. Alvarez M, Simonetta F, Baker J, Morrison AR, Wenokur AS, Pierini A, et al. Indirect Impact of PD-1/PD-L1 Blockade on a Murine Model of NK Cell Exhaustion. Front Immunol (2020) 11:7. doi: 10.3389/fimmu.2020.00007 
74. Porichis F, Hart MG, Massa A, Everett HL, Morou A, Richard J, et al. Immune Checkpoint Blockade Restores Hiv-Specific Cd4 T Cell Help for NK Cells. J Immunol (2018) 201(3):971-81. doi: 10.4049/jimmunol.1701551

75. Francisco LM, Salinas VH, Brown KE, Vanguri VK, Freeman GJ, Kuchroo VK, et al. Pd-L1 Regulates the Development, Maintenance, and Function of Induced Regulatory T Cells. J Exp Med (2009) 206(13):3015-29. doi: 10.1084/jem.20090847

76. Wang L, Pino-Lagos K, de Vries VC, Guleria I, Sayegh MH, Noelle RJ. Programmed Death 1 Ligand Signaling Regulates the Generation of Adaptive Foxp3+CD4+ Regulatory T Cells. Proc Natl Acad Sci USA (2008) 105(27):9331-6. doi: 10.1073/pnas.0710441105

77. Ghiringhelli F, Ménard C, Terme M, Flament C, Taieb J, Chaput N, et al. CD4+CD25+ Regulatory T Cells Inhibit Natural Killer Cell Functions in a Transforming Growth Factor-Beta-Dependent Manner. J Exp Med (2005) 202(8):1075-85. doi: 10.1084/jem.20051511

78. Keskin DB, Allan DS, Rybalov B, Andzelm MM, Stern JN, Kopcow HD, et al. Tgfbeta Promotes Conversion of CD16+ Peripheral Blood NK Cells Into CD16- NK Cells With Similarities to Decidual NK Cells. Proc Natl Acad Sci USA (2007) 104(9):3378-83. doi: 10.1073/pnas.0611098104

79. Wilson EB, El-Jawhari JJ, Neilson AL, Hall GD, Melcher AA, Meade JL, et al. Human Tumour Immune Evasion Via TGF-beta Blocks NK Cell Activation But Not Survival Allowing Therapeutic Restoration of Anti-Tumour Activity. PloS One (2011) 6(9):e22842. doi: 10.1371/journal.pone.0022842

80. Geng X, Li M, Cui B, Lu C, Liu X, Zhang P, et al. Cd4+Cd25+Foxp3+ Regulatory T Cells Suppress NKG2D-mediated NK Cell Cytotoxicity in Peripheral Blood. Med (Baltimore) (2019) 98(22):e15722-e. doi: 10.1097/ MD.0000000000015722

81. Sitrin J, Ring A, Garcia KC, Benoist C, Mathis D. Regulatory T Cells Control NK Cells in an Insulitic Lesion by Depriving Them of IL-2. J Exp Med (2013) 210(6):1153-65. doi: 10.1084/jem.20122248

82. Caudana P, Nunez NG, De La Rochere P, Pinto A, Denizeau J, Alonso R, et al. Il2/Anti-Il2 Complex Combined With CTLA-4, But Not Pd-1, Blockade Rescues Antitumor Nk Cell Function by Regulatory T-Cell Modulation. Cancer Immunol Res (2019) 7(3):443-57. doi: 10.1158/23266066.CIR-18-0697

83. Charych DH, Hoch U, Langowski JL, Lee SR, Addepalli MK, Kirk PB, et al. Nktr-214, an Engineered Cytokine With Biased Il2 Receptor Binding, Increased Tumor Exposure, and Marked Efficacy in Mouse Tumor Models. Clin Cancer Res (2016) 22(3):680-90. doi: 10.1158/1078-0432.CCR-15-1631

84. Hutmacher C, Gonzalo Nunez N, Liuzzi AR, Becher B, Neri D. Targeted Delivery of IL2 to the Tumor Stroma Potentiates the Action of Immune Checkpoint Inhibitors by Preferential Activation of NK and CD8(+) T Cells. Cancer Immunol Res (2019) 7(4):572-83. doi: 10.1158/2326-6066.CIR-18-0566

85. Ferlazzo G, Morandi B. Cross-Talks Between Natural Killer Cells and Distinct Subsets of Dendritic Cells. Front Immunol (2014) 5:159. doi: 10.3389/fimmu.2014.00159

86. Walzer T, Dalod M, Robbins SH, Zitvogel L, Vivier E. Natural-Killer Cells and Dendritic Cells: "L’union Fait La Force". Blood (2005) 106(7):2252-8. doi: 10.1182/blood-2005-03-1154

87. Moretta L, Ferlazzo G, Bottino C, Vitale M, Pende D, Mingari MC, et al. Effector and Regulatory Events During Natural Killer-Dendritic Cell Interactions. Immunol Rev (2006) 214:219-28. doi: 10.1111/j.1600065X.2006.00450.x

88. Lee SC, Srivastava RM, Lopez-Albaitero A, Ferrone S, Ferris RL. Natural Killer (NK): Dendritic Cell (DC) Cross Talk Induced by Therapeutic Monoclonal Antibody Triggers Tumor Antigen-Specific T Cell Immunity. Immunol Res (2011) 50(2-3):248-54. doi: 10.1007/s12026-011-8231-0

89. Salmon H, Idoyaga J, Rahman A, Leboeuf M, Remark R, Jordan S, et al. Expansion and Activation of CD103(+) Dendritic Cell Progenitors At the Tumor Site Enhances Tumor Responses to Therapeutic Pd-L1 and BRAF Inhibition. Immunity (2016) 44(4):924-38. doi: 10.1016/j.immuni.2016.03.012

90. Spranger S, Dai D, Horton B, Gajewski TF. Tumor-Residing Batf3 Dendritic Cells are Required for Effector T Cell Trafficking and Adoptive T Cell Therapy. Cancer Cell (2017) 31(5):711-23:e4. doi: 10.1016/j.ccell.2017.04.003

91. Oba T, Long MD, Keler T, Marsh HC, Minderman H, Abrams SI, et al. Overcoming Primary and Acquired Resistance to anti-PD-L1 Therapy by Induction and Activation of Tumor-Residing Cdc1s. Nat Commun (2020) 11 (1):5415. doi: 10.1038/s41467-020-19192-z
92. Yost KE, Satpathy AT, Wells DK, Qi Y, Wang C, Kageyama R, et al. Clonal Replacement of Tumor-Specific T Cells Following PD-1 Blockade. Nat Med (2019) 25(8):1251-9. doi: 10.1038/s41591-019-0522-3

93. Lin M, Luo H, Liang S, Chen J, Liu A, Niu L, et al. Pembrolizumab Plus Allogeneic NK Cells in Advanced non-Small Cell Lung Cancer Patients. J Clin Invest (2020) 130(5):2560-9. doi: 10.1172/JCI132712

94. Hoos A, Ibrahim R, Korman A, Abdallah K, Berman D, Shahabi V, et al. Development of Ipilimumab: Contribution to a New Paradigm for Cancer Immunotherapy. Semin Oncol (2010) 37(5):533-46. doi: 10.1053/ j.seminoncol.2010.09.015

95. Yervoy (ipilimumamab). Package Insert. Bristol-Myers Squibb Company (2020).

96. Kooshkaki O, Derakhshani A, Hosseinkhani N, Torabi M, Safaei S, Brunetti O, et al. Combination of Ipilimumab and Nivolumab in Cancers: From Clinical Practice to Ongoing Clinical Trials. Int J Mol Sci (2020) 21(12):4427. doi: $10.3390 /$ ijms 21124427

97. Stojanovic A, Fiegler N, Brunner-Weinzierl M, Cerwenka A. CTLA-4 is Expressed by Activated Mouse NK Cells and Inhibits NK Cell IFN-gamma Production in Response to Mature Dendritic Cells. J Immunol (2014) 192 (9):4184-91. doi: 10.4049/jimmunol.1302091

98. Jie HB, Schuler PJ, Lee SC, Srivastava RM, Argiris A, Ferrone S, et al. Ctla-4(+) Regulatory T Cells Increased in Cetuximab-Treated Head and Neck Cancer Patients Suppress NK Cell Cytotoxicity and Correlate With Poor Prognosis. Cancer Res (2015) 75(11):2200-10. doi: 10.1158/0008-5472.can-14-2788

99. Passariello M, Camorani S, Vetrei C, Ricci S, Cerchia L, De Lorenzo C. Ipilimumab and Its Derived EGFR Aptamer-Based Conjugate Induce Efficient Nk Cell Activation Against Cancer Cells. Cancers (Basel) (2020) 12(2):331. doi: 10.3390/cancers12020331

100. Laurent S, Queirolo P, Boero S, Salvi S, Piccioli P, Boccardo S, et al. The Engagement of CTLA-4 on Primary Melanoma Cell Lines Induces Antibody-Dependent Cellular Cytotoxicity and TNF- $\alpha$ Production. J Transl Med (2013) 11:108. doi: 10.1186/1479-5876-11-108

101. Sanseviero E, O’Brien EM, Karras JR, Shabaneh TB, Aksoy BA, Xu W, et al. Anti-CTLA-4 Activates Intratumoral NK Cells and Combined With IL15/ IL15R $\alpha$ Complexes Enhances Tumor Control. Cancer Immunol Res (2019) 7 (8):1371-80. doi: 10.1158/2326-6066.Cir-18-0386

102. Sáez-Borderías A, Romo N, Magri G, Gumá M, Angulo A, López-Botet M. Il12-Dependent Inducible Expression of the CD94/NKG2A Inhibitory Receptor Regulates CD94/NKG2C+ Nk Cell Function. J Immunol (2009) 182(2):829-36. doi: 10.4049/jimmunol.182.2.829

103. Wieten L, Mahaweni NM, Voorter CEM, Bos GMJ, Tilanus MGJ. Clinical and Immunological Significance of HLA-E in Stem Cell Transplantation and Cancer. Tissue Antigens (2014) 84(6):523-35. doi: 10.1111/tan.12478

104. André P, Denis C, Soulas C, Bourbon-Caillet C, Lopez J, Arnoux T, et al. Anti-NKG2A Mab Is a Checkpoint Inhibitor That Promotes Anti-Tumor Immunity by Unleashing Both T and NK Cells. Cell (2018) 175(7):1731-43 e13. doi: 10.1016/j.cell.2018.10.014

105. Berrien-Elliott MM, Cashen AF, Cubitt CC, Neal CC, Wong P, Wagner JA, et al. Multidimensional Analyses of Donor Memory-Like NK Cells Reveal New Associations With Response After Adoptive Immunotherapy for Leukemia. Cancer Discovery (2020) 10(12):1854-71. doi: 10.1158/2159-8290.Cd-20-0312

106. Kamiya T, Seow SV, Wong D, Robinson M, Campana D. Blocking Expression of Inhibitory Receptor NKG2A Overcomes Tumor Resistance to NK Cells. J Clin Invest (2019) 129(5):2094-106. doi: 10.1172/JCI123955

107. Marcus A, Mao AJ, Lensink-Vasan M, Wang L, Vance RE, Raulet DH. Tumor-Derived Cgamp Triggers a STING-Mediated Interferon Response in Non-tumor Cells to Activate the NK Cell Response. Immunity (2018) 49 (4):754-63 e4. doi: 10.1016/j.immuni.2018.09.016

108. Conry RM, Westbrook B, McKee S, Norwood TG. Talimogene Laherparepvec: First in Class Oncolytic Virotherapy. Hum Vaccin Immunother (2018) 14(4):839-46. doi: 10.1080/21645515.2017.1412896

109. Fujihara A, Kurooka M, Miki T, Kaneda Y. Intratumoral Injection of Inactivated Sendai Virus Particles Elicits Strong Antitumor Activity by Enhancing Local CXCL10 Expression and Systemic NK Cell Activation. Cancer Immunol Immunother (2008) 57(1):73-84. doi: 10.1007/s00262-007-0351-y

110. Saga K, Tamai K, Yamazaki T, Kaneda Y. Systemic Administration of a Novel Immune-Stimulatory Pseudovirion Suppresses Lung Metastatic Melanoma by Regionally Enhancing IFN-gamma Production. Clin Cancer Res (2013) 19(3):668-79. doi: 10.1158/1078-0432.CCR-12-1947 
111. Leung EYL, Ennis DP, Kennedy PR, Hansell C, Dowson S, Farquharson M, et al. Nk Cells Augment Oncolytic Adenovirus Cytotoxicity in Ovarian Cancer. Mol Ther Oncolytics (2020) 16:289-301. doi: 10.1016/j.omto.2020.02.001

112. Ricca JM, Oseledchyk A, Walther T, Liu C, Mangarin L, Merghoub T, et al. Pre-Existing Immunity to Oncolytic Virus Potentiates its Immunotherapeutic Efficacy. Mol Ther (2018) 26(4):1008-19. doi: 10.1016/ j.ymthe.2018.01.019

113. Kim Y, Yoo JY, Lee TJ, Liu J, Yu J, Caligiuri MA, et al. Complex Role of NK Cells in Regulation of Oncolytic Virus-Bortezomib Therapy. Proc Natl Acad Sci United States America (2018) 115(19):4927-32. doi: 10.1073/pnas. 1715295115

114. Kim N, Kim HS. Targeting Checkpoint Receptors and Molecules for Therapeutic Modulation of Natural Killer Cells. Front Immunol (2018) 9:2041. doi: 10.3389/fimmu.2018.02041

115. Klose C, Berchtold S, Schmidt M, Beil J, Smirnow I, Venturelli S, et al. Biological Treatment of Pediatric Sarcomas by Combined Virotherapy and NK Cell Therapy. BMC Cancer (2019) 19(1):1172. doi: 10.1186/s12885-019-6387-5

116. Li F, Sheng Y, Hou W, Sampath P, Byrd D, Thorne S, et al. CCL5-Armed Oncolytic Virus Augments CCR5-engineered NK Cell Infiltration and Antitumor Efficiency. J ImmunoTher Cancer (2020) 8(1):e000131. doi: 10.1136/jitc-2019-000131

117. Rajani K, Parrish C, Kottke T, Thompson J, Zaidi S, Ilett L, et al. Combination Therapy With Reovirus and Anti-PD-1 Blockade Controls Tumor Growth Through Innate and Adaptive Immune Responses. Mol Ther (2016) 24(1):166-74. doi: 10.1038/mt.2015.156

118. Chon HJ, Lee WS, Yang H, Kong SJ, Lee NK, Moon ES, et al. Tumor Microenvironment Remodeling by Intratumoral Oncolytic Vaccinia Virus Enhances the Efficacy of Immune-Checkpoint Blockade. Clin Cancer Res (2019) 25(5):1612-23. doi: 10.1158/1078-0432.Ccr-18-1932

119. Nakao S, Arai Y, Tasaki M, Yamashita M, Murakami R, Kawase T, et al. Intratumoral Expression of IL-7 and IL-12 Using an Oncolytic Virus Increases Systemic Sensitivity to Immune Checkpoint Blockade. Sci Transl Med (2020) 12(526):eaax7992. doi: 10.1126/scitranslmed.aax7992

120. Vijayakumar G, McCroskery S, Palese P. Engineering Newcastle Disease Virus as an Oncolytic Vector for Intratumoral Delivery of Immune Checkpoint Inhibitors and Immunocytokines. J Virol (2020) 94(3):e0167719. doi: 10.1128/jvi.01677-19

121. Miri SM, Ebrahimzadeh MS, Abdolalipour E, Yazdi M, Ravandi HH, Ghaemi A. Correction to: Synergy Between Hemagglutinin 2 (HA2) Subunit of Influenza Fusogenic Membrane Glycoprotein and Oncolytic Newcastle Disease Virus Suppressed Tumor Growth and Further Enhanced by Immune Checkpoint PD-1 Blockade. Cancer Cell Int (2020) 20:522. doi: 10.1186/s12935-020-01610-3

122. Lin C, Ren W, Luo Y, Li S, Chang Y, Li L, et al. Intratumoral Delivery of a PD-1-Blocking Scfv Encoded in Oncolytic Hsv-1 Promotes Antitumor Immunity and Synergizes With TIGIT Blockade. Cancer Immunol Res (2020) 8(5):632-47. doi: 10.1158/2326-6066.CIR-19-0628

123. Ribas A, Dummer R, Puzanov I, VanderWalde A, Andtbacka RHI, Michielin $\mathrm{O}$, et al. Oncolytic Virotherapy Promotes Intratumoral T Cell Infiltration and Improves Anti-PD-1 Immunotherapy. Cell (2017) 170(6):1109-19.e10. doi: 10.1016/j.cell.2017.08.027

124. Samson A, Scott KJ, Taggart D, West EJ, Wilson E, Nuovo GJ, et al. Intravenous Delivery of Oncolytic Reovirus to Brain Tumor Patients Immunologically Primes for Subsequent Checkpoint Blockade. Sci Transl Med (2018) 10(422):eaam7577. doi: 10.1126/scitranslmed.aam7577

125. Wu J, Sun L, Chen X, Du F, Shi H, Chen C, et al. Cyclic GMP-AMP is an Endogenous Second Messenger in Innate Immune Signaling by Cytosolic DNA. Science (2013) 339(6121):826-30. doi: 10.1126/science.1229963

126. Ishikawa H, Ma Z, Barber GN. STING Regulates Intracellular DNAmediated, Type I Interferon-Dependent Innate Immunity. Nature (2009) 461(7265):788-92. doi: 10.1038/nature08476

127. Ishikawa H, Barber GN. STING is an Endoplasmic Reticulum Adaptor That Facilitates Innate Immune Signalling. Nature (2008) 455(7213):674-8. doi: 10.1038/nature07317

128. Lam AR, Bert NL, Ho SS, Shen YJ, Tang LF, Xiong GM, et al. RAE1 Ligands for the NKG2D Receptor are Regulated by STING-dependent DNA Sensor Pathways in Lymphoma. Cancer Res (2014) 74(8):2193-203. doi: 10.1158/ 0008-5472.CAN-13-1703
129. Xia T, Konno H, Ahn J, Barber GN. Deregulation of STING Signaling in Colorectal Carcinoma Constrains Dna Damage Responses and Correlates With Tumorigenesis. Cell Rep (2016) 14(2):282-97. doi: 10.1016/j.celrep.2015.12.029

130. Xia T, Konno H, Barber GN. Recurrent Loss of STING Signaling in Melanoma Correlates With Susceptibility to Viral Oncolysis. Cancer Res (2016) 76(22):6747-59. doi: 10.1158/0008-5472.CAN-16-1404

131. Li A, Yi M, Qin S, Song Y, Chu Q, Wu K. Activating cGAS-STING Pathway for the Optimal Effect of Cancer Immunotherapy. J Hematol Oncol (2019) 12 (1):35. doi: 10.1186/s13045-019-0721-x

132. Song S, Peng P, Tang Z, Zhao J, Wu W, Li H, et al. Decreased Expression of STING Predicts Poor Prognosis in Patients With Gastric Cancer. Sci Rep (2017) 7:39858. doi: 10.1038/srep39858

133. An X, Zhu Y, Zheng T, Wang G, Zhang M, Li J, et al. An Analysis of the Expression and Association With Immune Cell Infiltration of the Cgas/ STING Pathway in Pan-Cancer. Mol Ther Nucleic Acids (2019) 14:80-9. doi: 10.1016/j.omtn.2018.11.003

134. Foote JB, Kok M, Leatherman JM, Armstrong TD, Marcinkowski BC, Ojalvo LS, et al. A STING Agonist Given With OX40 Receptor and PD-L1 Modulators Primes Immunity and Reduces Tumor Growth in Tolerized Mice. Cancer Immunol Res (2017) 5(6):468-79. doi: 10.1158/2326-6066.CIR16-0284

135. Francica BJ, Ghasemzadeh A, Desbien AL, Theodros D, Sivick KE, Reiner GL, et al. Tnfalpha and Radioresistant Stromal Cells are Essential for Therapeutic Efficacy of Cyclic Dinucleotide STING Agonists in Nonimmunogenic Tumors. Cancer Immunol Res (2018) 6(4):422-33. doi: 10.1158/2326-6066.CIR-17-0263

136. Sivick KE, Desbien AL, Glickman LH, Reiner GL, Corrales L, Surh NH, et al. Magnitude of Therapeutic Sting Activation Determines Cd8(+) T CellMediated Anti-tumor Immunity. Cell Rep (2018) 25(11):3074-85 e5. doi: 10.1016/j.celrep.2018.11.047

137. Nicolai CJ, Wolf N, Chang IC, Kirn G, Marcus A, Ndubaku CO, et al. NK Cells Mediate Clearance of CD8(+) T Cell-Resistant Tumors in Response to STING Agonists. Sci Immunol (2020) 5(45):eaaz2738. doi: 10.1126/ sciimmunol.aaz2738

138. Melaiu O, Lucarini V, Cifaldi L, Fruci D. Influence of the Tumor Microenvironment on NK Cell Function in Solid Tumors. Front Immunol (2020) 10:3038. doi: 10.3389/fimmu.2019.03038

139. Imai K, Matsuyama S, Miyake S, Suga K, Nakachi K. Natural Cytotoxic Activity of Peripheral-Blood Lymphocytes and Cancer Incidence: An 11Year Follow-Up Study of a General Population. Lancet (2000) 356 (9244):1795-9. doi: 10.1016/s0140-6736(00)03231-1

140. Platonova S, Cherfils-Vicini J, Damotte D, Crozet L, Vieillard V, Validire P, et al. Profound Coordinated Alterations of Intratumoral Nk Cell Phenotype and Function in Lung Carcinoma. Cancer Res (2011) 71(16):5412-22. doi: 10.1158/0008-5472.can-10-4179

141. Mamessier E, Sylvain A, Thibult ML, Houvenaeghel G, Jacquemier J, Castellano R, et al. Human Breast Cancer Cells Enhance Self Tolerance by Promoting Evasion From NK Cell Antitumor Immunity. J Clin Invest (2011) 121(9):3609-22. doi: 10.1172/JCI45816

142. Easom NJW, Stegmann KA, Swadling L, Pallett LJ, Burton AR, Odera D, et al. Il-15 Overcomes Hepatocellular Carcinoma-Induced Nk Cell Dysfunction. Front Immunol (2018) 9:1009. doi: 10.3389/fimmu.2018.01009

143. Zhang R, Qi F, Zhao F, Li G, Shao S, Zhang X, et al. Cancer-Associated Fibroblasts Enhance Tumor-Associated Macrophages Enrichment and Suppress NK Cells Function in Colorectal Cancer. Cell Death Dis (2019) 10(4):273. doi: 10.1038/s41419-019-1435-2

144. Baginska J, Viry E, Paggetti J, Medves S, Berchem G, Moussay E, et al. The Critical Role of the Tumor Microenvironment in Shaping Natural Killer Cell-Mediated Anti-Tumor Immunity. Front Immunol (2013) 4:490. doi: 10.3389/fimmu.2013.00490

145. Otegbeye F, Ojo E, Moreton S, Mackowski N, Lee DA, de Lima M, et al. Inhibiting TGF-beta Signaling Preserves the Function of Highly Activated, In Vitro Expanded Natural Killer Cells in AML and Colon Cancer Models. PloS One (2018) 13(1):e0191358. doi: 10.1371/journal.pone.0191358

146. Lee Hm, Kim K-S, Kim J. A Comparative Study of the Effects of Inhibitory Cytokines on Human Natural Killer Cells and the Mechanistic Features of Transforming Growth Factor-Beta. Cell Immunol (2014) 290(1):52-61. doi: 10.1016/j.cellimm.2014.05.001 
147. Mariathasan S, Turley SJ, Nickles D, Castiglioni A, Yuen K, Wang Y, et al. Tgf $\beta$ Attenuates Tumour Response to PD-L1 Blockade by Contributing to Exclusion of T Cells. Nature (2018) 554(7693):544-8. doi: 10.1038/nature25501

148. Regis S, Caliendo F, Dondero A, Casu B, Romano F, Loiacono F, et al. Tgf- $\beta 1$ Downregulates the Expression of CX3CR1 by Inducing miR-27a-5p in Primary Human NK Cells. Front Immunol (2017) 8:868. doi: 10.3389/ fimmu.2017.00868

149. Slattery K, Zaiatz-Bittencourt V, Woods E, Brennan K, Marks S, Chew S, et al. Tgf $\beta$ Drives Mitochondrial Dysfunction in Peripheral Blood NK Cells During Metastatic Breast Cancer. bioRxiv (2019) 9:e002044. doi: 10.1101/ 648501

150. Keating SE, Zaiatz-Bittencourt V, Loftus RM, Keane C, Brennan K, Finlay DK, et al. Metabolic Reprogramming Supports Ifn- $\gamma$ Production by CD56 ${ }^{\text {bright }}$ Nk Cells. J Immunol (2016) 196(6):2552-60. doi: 10.4049/ jimmunol.1501783

151. Huang CH, Liao YJ, Chiou TJ, Huang HT, Lin YH, Twu YC. Tgf- $\beta$ Regulated Leukemia Cell Susceptibility Against NK Targeting Through the DownRegulation of the CD48 Expression. Immunobiology (2019) 224(5):649-58. doi: 10.1016/j.imbio.2019.07.002

152. Gao Y, Souza-Fonseca-Guimaraes F, Bald T, Ng SS, Young A, Ngiow SF, et al. Tumor Immunoevasion by the Conversion of Effector NK Cells Into Type 1 Innate Lymphoid Cells. Nat Immunol (2017) 18(9):1004-15. doi: $10.1038 /$ ni.3800

153. Lind H, Gameiro SR, Jochems C, Donahue RN, Strauss J, Gulley JLMD, et al. Dual Targeting of TGF- $\beta$ and PD-L1 Via a Bifunctional Anti-PD-L1/TGFBrii Agent: Status of Preclinical and Clinical Advances. J Immunother Cancer (2020) 8(1):e000433. doi: 10.1136/jitc-2019-000433

154. Gooding R, Riches P, Dadian G, Moore J, Gore M. Increased Soluble Interleukin-2 Receptor Concentration in Plasma Predicts a Decreased Cellular Response to IL-2. Br J Cancer (1995) 72(2):452-5. doi: 10.1038/ bjc. 1995.354

155. Viviani S, Camerini E, Bonfante V, Santoro A, Balzarotti M, Fornier M, et al. Soluble Interleukin-2 Receptors (sIL-2R) in Hodgkin's Disease: Outcome and Clinical Implications. Br J Cancer (1998) 77(6):992-7. doi: 10.1038/ bjc. 1998.163

156. Jiang X, Ellison SJ, Alarid ET, Shapiro DJ. Interplay Between the Levels of Estrogen and Estrogen Receptor Controls the Level of the Granzyme Inhibitor, Proteinase Inhibitor 9 and Susceptibility to Immune Surveillance by Natural Killer Cells. Oncogene (2007) 26:4106. doi: 10.1038/ sj.onc. 1210197

157. Devillier R, Chrétien AS, Pagliardini T, Salem N, Blaise D, Olive D. Mechanisms of NK Cell Dysfunction in the Tumor Microenvironment and Current Clinical Approaches to Harness NK Cell Potential for Immunotherapy. J Leukoc Biol (2020) 1-18. doi: 10.1002/jlb.5mr0920-198rr

158. Rossi GR, Trindade ES, Souza-Fonseca-Guimaraes F. Tumor Microenvironment-Associated Extracellular Matrix Components Regulate Nk Cell Function. Front Immunol (2020) 11:73. doi: 10.3389/ fimmu.2020.00073

159. Chouaib S, Noman MZ, Kosmatopoulos K, Curran MA. Hypoxic Stress: Obstacles and Opportunities for Innovative Immunotherapy of Cancer. Oncogene (2017) 36(4):439-45. doi: 10.1038/onc.2016.225

160. Hatfield SM, Kjaergaard J, Lukashev D, Schreiber TH, Belikoff B, Abbott R, et al. Immunological Mechanisms of the Antitumor Effects of Supplemental Oxygenation. Sci Transl Med (2015) 7(277):277ra30. doi: 10.1126/ scitranslmed.aaa1260

161. Yamada N, Yamanegi K, Ohyama H, Hata M, Nakasho K, Futani H, et al. Hypoxia Downregulates the Expression of Cell Surface MICA Without Increasing Soluble MICA in Osteosarcoma Cells in a HIF-1alpha-dependent Manner. Int J Oncol (2012) 41(6):2005-12. doi: 10.3892/ijo.2012.1630

162. Demicheli R, Valagussa P, Bonadonna G. Does Surgery Modify Growth Kinetics of Breast Cancer Micrometastases? Br J Cancer (2001) 85(4):490-2. doi: 10.1054/bjoc.2001.1969

163. Tai L-H, de Souza CT, Bélanger S, Ly L, Alkayyal AA, Zhang J, et al. Preventing Postoperative Metastatic Disease by Inhibiting Surgery-Induced Dysfunction in Natural Killer Cells. Cancer Res (2013) 73(1):97-107. doi: 10.1158/0008-5472.can-12-1993

164. Niavarani SR, Lawson C, Bakos O, Boudaud M, Batenchuk C, Rouleau S, et al. Lipid Accumulation Impairs Natural Killer Cell Cytotoxicity and
Tumor Control in the Postoperative Period. BMC Cancer (2019) 19 (1):823. doi: $10.1186 / \mathrm{s} 12885-019-6045-y$

165. Seth R, Tai L-H, Falls T, de Souza CT, Bell JC, Carrier M, et al. Surgical Stress Promotes the Development of Cancer Metastases by a CoagulationDependent Mechanism Involving Natural Killer Cells in a Murine Model. Ann Surg (2013) 258(1):158-68. doi: 10.1097/SLA.0b013e31826fcbdb

166. Kim R. Effects of Surgery and Anesthetic Choice on Immunosuppression and Cancer Recurrence. J Trans Med (2018) 16(1):8. doi: 10.1186/s12967-0181389-7

167. de Oliveira GS, Ahmad S, Schink JC, Singh DK, Fitzgerald PC, McCarthy RJ. Intraoperative Neuraxial Anesthesia But Not Postoperative Neuraxial Analgesia is Associated With Increased Relapse-Free Survival in Ovarian Cancer Patients After Primary Cytoreductive Surgery. Reg Anaesth Pain Med (2011) 36(3):271-7-7. doi: 10.1097/AAP.0b013e318217aada

168. Exadaktylos AK, Buggy DJ, Moriarty DC, Mascha E, Sessler DI. Can Anesthetic Technique for Primary Breast Cancer Surgery Affect Recurrence or Metastasis? Anesthesiology (2006) 105(4):660-4. doi: 10.1097/00000542-200610000-00008

169. Gupta A, Björnsson A, Fredriksson M, Hallböök O, Eintrei C. Reduction in Mortality After Epidural Anaesthesia and Analgesia in Patients Undergoing Rectal But Not Colonic Cancer Surgery: A Retrospective Analysis of Data From 655 Patients in Central Sweden. Br J Anaesth (2011) 107(2):164-70. doi: $10.1093 /$ bja/aer100

170. Reeh M, Ghadban T, Dedow J, Vettorazzi E, Uzunoglu FG, Nentwich M, et al. Allogenic Blood Transfusion is Associated With Poor Perioperative and Long-Term Outcome in Esophageal Cancer. World J Surg (2017) 41(1):20815. doi: 10.1007/s00268-016-3730-8

171. Ghio M, Contini P, Negrini S, Mazzei C, Zocchi MR, Poggi A. Down Regulation of Human Natural Killer Cell-Mediated Cytolysis Induced by Blood Transfusion: Role of Transforming Growth Factor-Beta(1), Soluble Fas Ligand, and Soluble Class I Human Leukocyte Antigen. Transfusion (2011) 51(7):1567-73. doi: 10.1111/j.1537-2995.2010.03000.x

172. Brochner AC, Mikkelsen S, Hegelund I, Hokland M, Mogensen O, Toft P. The Immune Response is Affected for At Least Three Weeks After Extensive Surgery for Ovarian Cancer. Danish Med J (2016) 63(6):A5243.

173. Iannone F, Porzia A, Peruzzi G, Birarelli P, Milana B, Sacco L, et al. Effect of Surgery on Pancreatic Tumor-Dependent Lymphocyte Asset: Modulation of Natural Killer Cell Frequency and Cytotoxic Function. Pancreas (2015) 44 (3):386-93. doi: 10.1097/MPA.0000000000000288

174. Velásquez JF, Ramírez MF, Ai D, Lewis V, Cata JP. Impaired Immune Function in Patients Undergoing Surgery for Bone Cancer. Anticancer Res (2015) 35(10):5461-6.

175. McCoy MJ, Lake RA, van der Most RG, Dick IM, Nowak AK. PostChemotherapy T-cell Recovery is a Marker of Improved Survival in Patients With Advanced Thoracic Malignancies. Br J Cancer (2012) 107 (7):1107-15. doi: 10.1038/bjc.2012.362

176. Onyema OO, Decoster L, Njemini R, Forti LN, Bautmans I, De Waele M, et al. Chemotherapy-Induced Changes and Immunosenescence of CD8+ TCells in Patients With Breast Cancer. Anticancer Res (2015) 35(3):1481-9.

177. Mozaffari F, Lindemalm C, Choudhury A, Granstam-Björneklett H, Helander I, Lekander M, et al. NK-Cell and T-cell Functions in Patients With Breast Cancer: Effects of Surgery and Adjuvant Chemo- and Radiotherapy. Br J Cancer (2007) 97:105. doi: 10.1038/sj.bjc.6603840

178. Nakano R, Ohira M, Yano T, Imaoka Y, Tanaka Y, Ohdan H. Hepatic Irradiation Persistently Eliminates Liver Resident NK Cells. PloS One (2018) 13(6):e0198904. doi: 10.1371/journal.pone.0198904

179. O’Donnell PV, Luznik L, Jones RJ, Vogelsang GB, Leffell MS, Phelps M, et al. Nonmyeloablative Bone Marrow Transplantation From Partially HLAmismatched Related Donors Using Posttransplantation Cyclophosphamide. Biol Blood Marrow Transplant (2002) 8(7):377-86. doi: 10.1053/ bbmt.2002.v8.pm12171484

180. Ciurea SO, Zhang M-J, Bacigalupo AA, Bashey A, Appelbaum FR, Aljitawi OS, et al. Haploidentical Transplant With Posttransplant Cyclophosphamide vs Matched Unrelated Donor Transplant for Acute Myeloid Leukemia. Blood (2015) 126(8):1033-40. doi: 10.1182/blood-2015-04-639831

181. Luznik L, Jalla S, Engstrom LW, Iannone R, Fuchs EJ. Durable Engraftment of Major Histocompatibility Complex-Incompatible Cells After Nonmyeloablative Conditioning With Fludarabine, Low-Dose Total Body 
Irradiation, and Posttransplantation Cyclophosphamide. Blood (2001) 98 (12):3456-64. doi: 10.1182/blood.V98.12.3456

182. Russo A, Oliveira G, Berglund S, Greco R, Gambacorta V, Cieri N, et al. NK Cell Recovery After Haploidentical HSCT With Posttransplant Cyclophosphamide: Dynamics and Clinical Implications. Blood (2018) 131 (2):247-62. doi: 10.1182/blood-2017-05-780668

183. Comparing the Outcome of Immunotherapy-Based Drug Combination Therapy With or Without Surgery to Remove the Kidney in Metastatic Kidney Cancer, the PROBE Trial . Available at: https://ClinicalTrials.gov/ show/NCT04510597.

184. Niedzwiedz CL, Knifton L, Robb KA, Katikireddi SV, Smith DJ. Depression and Anxiety Among People Living With and Beyond Cancer: A Growing Clinical and Research Priority. BMC Cancer (2019) 19(1):943. doi: 10.1186/ s12885-019-6181-4

185. Krebber AM, Buffart LM, Kleijn G, Riepma IC, de Bree R, Leemans CR, et al. Prevalence of Depression in Cancer Patients: A Meta-Analysis of Diagnostic Interviews and Self-Report Instruments. Psychooncology (2014) 23(2):12130. doi: 10.1002/pon.3409

186. Hartung TJ, Brahler E, Faller H, Harter M, Hinz A, Johansen C, et al. The Risk of Being Depressed is Significantly Higher in Cancer Patients Than in the General Population: Prevalence and Severity of Depressive Symptoms Across Major Cancer Types. Eur J Cancer (2017) 72:46-53. doi: 10.1016/ j.ejca.2016.11.017

187. Quatrini L, Wieduwild E, Escaliere B, Filtjens J, Chasson L, Laprie C, et al. Endogenous Glucocorticoids Control Host Resistance to Viral Infection Through the Tissue-Specific Regulation of PD-1 Expression on NK Cells. Nat Immunol (2018) 19(9):954-62. doi: 10.1038/s41590-018-0185-0

188. Capellino S, Claus M, Watzl C. Regulation of Natural Killer Cell Activity by Glucocorticoids, Serotonin, Dopamine, and Epinephrine. Cell Mol Immunol (2020) 17(7):705-11. doi: 10.1038/s41423-020-0477-9

189. Yang H, Xia L, Chen J, Zhang S, Martin V, Li Q, et al. Stress-GlucocorticoidTSC22D3 Axis Compromises Therapy-Induced Antitumor Immunity. Nat Med (2019) 25(9):1428-41. doi: 10.1038/s41591-019-0566-4

190. Denman CJ, Senyukov VV, Somanchi SS, Phatarpekar PV, Kopp LM, Johnson JL, et al. Membrane-Bound IL-21 Promotes Sustained Ex Vivo Proliferation of Human Natural Killer Cells. PloS One (2012) 7(1):e30264. doi: 10.1371 /journal.pone. 0030264

191. Fujisaki H, Kakuda H, Shimasaki N, Imai C, Ma J, Lockey T, et al. Expansion of Highly Cytotoxic Human Natural Killer Cells for Cancer Cell Therapy. Cancer Res (2009) 69(9):4010-7. doi: 10.1158/0008-5472.can-08-3712

192. Ciurea SO, Saliba R, Soebbing D, Rondon G, Cao K, Ahmed S, et al. Enhanced Antitumor Effect and Lower Viral Reactivation With High Doses of Ex Vivo Expanded NK Cells Administered After Haploidentical Transplantation. J Clin Oncol (2019) 37(8_suppl):74. doi: 10.1200/ JCO.2019.37.8_suppl.74

193. Ciurea SO, Silla L, Cao K, Rezvani K, Shpall EJ, Soebbing D, et al. Initial Results of Two Phase I Trials Delivering mbIL-21 Ex Vivo Expanded Haploidentical NK Cells After Fludarabine/Cytarabine for Patients With Relapsed/Refractory Myeloid Leukemias. J Clin Oncol (2018) 36 (15_suppl):7008. doi: 10.1200/JCO.2018.36.15_suppl.7008

194. Oyer JL, Igarashi RY, Kulikowski AR, Colosimo DA, Solh MM, Zakari A, et al. Generation of Highly Cytotoxic Natural Killer Cells for Treatment of Acute Myelogenous Leukemia Using a Feeder-Free, Particle-Based Approach. Biol Blood Marrow Transpl (2015) 21(4):632-9. doi: 10.1016/ j.bbmt.2014.12.037

195. Oyer JL, Pandey V, Igarashi RY, Somanchi SS, Zakari A, Solh M, et al. Natural Killer Cells Stimulated With PM21 Particles Expand and Biodistribute In Vivo: Clinical Implications for Cancer Treatment. Cytotherapy (2016) 18(5):653-63. doi: 10.1016/j.jcyt.2016.02.006

196. Romee R, Schneider SE, Leong JW, Chase JM, Keppel CR, Sullivan RP, et al. Cytokine Activation Induces Human Memory-Like NK Cells. Blood (2012) 120(24):4751-60. doi: 10.1182/blood-2012-04-419283

197. Romee R, Rosario M, Berrien-Elliott MM, Wagner JA, Jewell BA, Schappe T, et al. Cytokine-Induced Memory-Like Natural Killer Cells Exhibit Enhanced Responses Against Myeloid Leukemia. Sci Transl Med (2016) 8 (357):357ra123. doi: 10.1126/scitranslmed.aaf2341
198. Ni J, Holsken O, Miller M, Hammer Q, Luetke-Eversloh M, Romagnani C, et al. Adoptively Transferred Natural Killer Cells Maintain Long-Term Antitumor Activity by Epigenetic Imprinting and CD4(+) T Cell Help. Oncoimmunology (2016) 5(9):e1219009. doi: 10.1080/2162402x.2016.1219009

199. Spanholtz J, Tordoir M, Eissens D, Preijers F, van der Meer A, Joosten I, et al. High Log-Scale Expansion of Functional Human Natural Killer Cells From Umbilical Cord Blood CD34-positive Cells for Adoptive Cancer Immunotherapy. PloS One (2010) 5(2):e9221. doi: 10.1371/journal.pone.0009221

200. Knorr DA, Ni Z, Hermanson D, Hexum MK, Bendzick L, Cooper LJ, et al. Clinical-Scale Derivation of Natural Killer Cells From Human Pluripotent Stem Cells for Cancer Therapy. Stem Cells Transl Med (2013) 2(4):274-83. doi: $10.5966 / \mathrm{sctm} .2012-0084$

201. Fang F, Wang W, Chen M, Tian Z, Xiao W. Technical Advances in NK CellBased Cellular Immunotherapy. Cancer Biol Med (2019) 16(4):647-54. doi: 10.20892/j.issn.2095-3941.2019.0187

202. Michen S, Frosch J, Füssel M, Schackert G, Momburg F, Temme A. Artificial Feeder Cells Expressing Ligands for Killer Cell Immunoglobulin-Like Receptors and CD94/NKG2A for Expansion of Functional Primary Natural Killer Cells With Tolerance to Self. Cytotherapy (2020) 22(7):35468. doi: 10.1016/j.jcyt.2020.02.004

203. Shimasaki N, Coustan-Smith E, Kamiya T, Campana D. Expanded and Armed Natural Killer Cells for Cancer Treatment. Cytotherapy (2016) 18 (11):1422-34. doi: 10.1016/j.jcyt.2016.06.013

204. Villalba M, Alexia C, Bellin-Robert A, Fayd'herbe de Maudave A, Gitenay D. Non-Genetically Improving the Natural Cytotoxicity of Natural Killer (Nk) Cells. Front Immunol (2020) 10:3026. doi: 10.3389/fimmu.2019.03026

205. Burger MC, Zhang C, Harter PN, Romanski A, Strassheimer F, Senft C, et al. Car-Engineered NK Cells for the Treatment of Glioblastoma: Turning Innate Effectors Into Precision Tools for Cancer Immunotherapy. Front Immunol (2019) 10:2683. doi: 10.3389/fimmu.2019.02683

206. Liu E, Marin D, Banerjee P, Macapinlac HA, Thompson P, Basar R, et al. Use of CAR-Transduced Natural Killer Cells in CD19-Positive Lymphoid Tumors. N Engl J Med (2020) 382(6):545-53. doi: 10.1056/NEJMoa1910607

207. Granzin M, Wagner J, Köhl U, Cerwenka A, Huppert V, Ullrich E. Shaping of Natural Killer Cell Antitumor Activity by Ex Vivo Cultivation. Front Immunol (2017) 8:458. doi: 10.3389/fimmu.2017.00458

208. Pfefferle A, Huntington ND. You Have Got a Fast Car: Chimeric Antigen Receptor Nk Cells in Cancer Therapy. Cancers (Basel) (2020) 12(3):706. doi: 10.3390/cancers12030706

209. Daher M, Rezvani K. Outlook for New Car-Based Therapies With a Focus on CAR Nk Cells: What Lies Beyond Car-Engineered T Cells in the Race Against Cancer. Cancer Discovery (2020) 11(1):45-58. doi: 10.1158/21598290.CD-20-0556

210. Xie G, Dong H, Liang Y, Ham JD, Rizwan R, Chen J. Car-NK Cells: A Promising Cellular Immunotherapy for Cancer. EBioMedicine (2020) 59:102975. doi: 10.1016/j.ebiom.2020.102975

211. Lamb MG, Rangarajan HG, Tullius BP, Lee DA. Natural Killer Cell Therapy for Hematologic Malignancies: Successes, Challenges, and the Future. Stem Cell Res Ther (2021) 12(1):211. doi: 10.1186/s13287-021-02277-x

212. Lee DA. Cellular Therapy: Adoptive Immunotherapy With Expanded Natural Killer Cells. Immunol Rev (2019) 290(1):85-99. doi: 10.1111/imr.12793

Conflict of Interest: AC has intellectual property licensed to and holds ownership interest in as well as consults for Kiadis Pharma. AC also received research support from Kiadis Pharma.

The remaining authors declare that the research was conducted in the absence of any commercial or financial relationships that could be construed as a potential conflict of interest.

Copyright () 2021 Shaver, Croom-Perez and Copik. This is an open-access article distributed under the terms of the Creative Commons Attribution License (CC BY). The use, distribution or reproduction in other forums is permitted, provided the original author(s) and the copyright owner(s) are credited and that the original publication in this journal is cited, in accordance with accepted academic practice. No use, distribution or reproduction is permitted which does not comply with these terms. 


\section{GLOSSARY}

\begin{tabular}{|c|c|}
\hline 2B4 & CD244 natural killer cell receptor 2B4 \\
\hline 4-1BBL & 4-1BB ligand \\
\hline ADCC & antibody-dependent cell-mediated cytotoxicity \\
\hline AML & acute myeloid leukemia \\
\hline AMP & adenosine monophosphate \\
\hline APCs & antigen-presenting cells \\
\hline CCL3 & C-C motif chemokine ligand 3 \\
\hline CCL5 & C-C motif chemokine ligand 5 \\
\hline CCR5 & C-C motif chemokine receptor 5 \\
\hline CD16 & Fc fragment of IgG receptor III\&alpha \\
\hline CD25 & IL2R\&alpha interleukin 2 receptor subunit alpha \\
\hline CD39 & ENTPD1 ectonucleoside triphosphate diphosphohydrolase 1 \\
\hline CD54 & ICAM1 intercellular adhesion molecule 1 \\
\hline CD73 & NT5E 5\&rsquo;-nucleotidase ecto \\
\hline CD107a & LAMP1 lysosomal associated membrane protein 1 \\
\hline CD137 & 4-1BB/TNFRSF9 TNF receptor superfamily member 9 \\
\hline cDC1 & conventional type 1 dendritic cells \\
\hline cGAMP & cyclic guanosine monophosphate-adenosine monophosphate \\
\hline cGAS & $\begin{array}{l}\text { cyclic guanosine monophosphate-adenosine monophosphate } \\
\text { synthase }\end{array}$ \\
\hline $\begin{array}{l}\text { CIML NK } \\
\text { cells }\end{array}$ & cytokine-induced memory-like Natural Killer cells \\
\hline CTLA-4 & cytotoxic T-lymphocyte associated protein 4 \\
\hline $\mathrm{CX}_{3} \mathrm{CL} 1$ & C-X3-C motif chemokine ligand 1 \\
\hline $\mathrm{CX}_{3} \mathrm{CR} 1$ & C-X3-C motif chemokine receptor 1 \\
\hline CXCL9 & C-X-C motif chemokine ligand 9 \\
\hline CXCL10 & C-X-C motif chemokine ligand 10 \\
\hline DCs & dendritic cells \\
\hline DNAM-1 & CD226 molecule \\
\hline ERK & extracellular signal-regulated kinase \\
\hline FasL & Fas ligand \\
\hline FBP1 & fructose-bisphosphatase 1 \\
\hline FLT3LG & fms related receptor tyrosine kinase 3 ligand \\
\hline Foxp3 & forkhead box P3 \\
\hline GMP & cyclic guanosine monophosphate \\
\hline HER2/NEU & erb-b2 receptor tyrosine kinase 2 \\
\hline
\end{tabular}

(Continued)

\section{Continued}

\begin{tabular}{|c|c|}
\hline HLA & human leukocyte antigen \\
\hline HLA-E & major histocompatibility complex \\
\hline class I & E \\
\hline HPA & hypothalamic-pituitary-adrenal \\
\hline HVJ-E & hemagglutinating virus of Japan-Envelope \\
\hline IFN & interferon \\
\hline IRF3 & interferon regulatory factor 3 \\
\hline iPSCs & induced pluripotent stem cells \\
\hline IRF3 & interferon regulatory factor 3 \\
\hline $\mathrm{KIR}$ & killer cell immunoglobulin like receptor \\
\hline mblL21 & membrane bound IL-21 \\
\hline MDSCs & myeloid-derived suppressor cells \\
\hline MEK & mitogen-activated protein kinase \\
\hline $\mathrm{MHC}$ & major histocompatibility complex \\
\hline MSI-H/dMMR & microsatellite instability-high or mismatch repair deficient \\
\hline NCRs & natural cytotoxicity receptors \\
\hline NDV & Newcastle Disease Virus \\
\hline$N F-\kappa \beta$ & nuclear factor $\kappa \beta$ \\
\hline NK cells & Natural Killer cells \\
\hline NKG2A & KLRC1 killer cell lectin like receptor C1 \\
\hline NKG2D & KLRK1 killer cell lectin like receptor K1 \\
\hline NKp30 & NCR3 natural cytotoxicity triggering receptor 3 \\
\hline NSCLC & non-small cell lung cancer \\
\hline OV & oncolytic virus \\
\hline PBMCs & peripheral blood mononuclear cells \\
\hline PD-1 & PDCD1 programmed cell death 1 \\
\hline PD-L1 & CD274/programmed cell death 1 ligand 1 \\
\hline $\begin{array}{l}\text { PM21- } \\
\text { particles }\end{array}$ & plasma membrane particles \\
\hline RAE-1 & retinoic acid early inducible 1 \\
\hline S100 & ADU-S100 \\
\hline STING & stimulation of interferon genes \\
\hline TCR & T cell receptor \\
\hline TGF- $\beta$ & transforming growth factor beta \\
\hline TIGIT & T cell immunoreceptor with Ig and ITIM domains \\
\hline TIM-3 & T cell immunoglobulin and mucin domain containing 4 \\
\hline TNF- $\alpha$ & tumor necrosis factor alpha \\
\hline Tregs & regulatory T cells \\
\hline XCL1 & X-C motif chemokine ligand 1. \\
\hline
\end{tabular}

